\title{
Investigation of Innovative Synthesis of Biologically Active Compounds on the Basis of Newly Developed Reactions
}

\author{
Toshio Honda \\ Faculty of Pharmaceutical Sciences, Hoshi University; 2-4-41 Ebara, \\ Shinagawa-ku, Tokyo 142-8501, Japan. \\ Received February 29, 2012
}

\begin{abstract}
Synthesis of biologically active compounds, including natural products and pharmaceutical agents, is an important and interesting research area since the large structural diversity and complexity of bioactive compounds make them an important source of leads and scaffolds in drug discovery and development. Many structurally and also biologically interesting compounds, including marine natural products, have been isolated from nature and have also been prepared on the basis of a computational design for the purpose of developing medicinal chemistry. In order to obtain a wide variety of derivatives of biologically active compounds from the viewpoint of medicinal chemistry, it is essential to establish efficient synthetic procedures for desired targets. Newly developed reactions should also be used for efficient synthesis of desired compounds. Thus, recent progress in the synthesis of biologically active compounds by focusing on the development of new reactions is summarized in this review article.
\end{abstract}

Key words bioactive compound; samarium diiodide; kinetic resolution; aromatic oxidation; ring-closing metathesis; Honda-Reformatsky reaction

\section{Introduction}

Establishment of synthetic methodology and/or synthetic strategy for relevant organic compounds, such as natural products and analogues, agrochemicals, diagnostics, and other kinds of material, with the objection of searching for new potential biological compounds is an important subject in medicinal chemistry. To synthesize desired biologically active compounds having structural complexity, new and highly selective methods should be developed to establish efficient synthetic procedures. Synthetic methodology should also be designed in such a way that it allows access to diversified substance libraries by routine use of the newly designed way.

Natural products have always been a successful pool of molecules from which the pharmaceutical industry can find novel medicinal agents. Natural products with their wide range of structural and stereochemical features continue to be the subject of medicinal investigations and also to provide challenging synthetic targets. Natural products have, over the years, provoked an extraordinary amount of activity by synthetic organic chemists.

Thus, the synthesis of biologically active natural products is still a main topic in academic and industrial chemistry, since natural compounds themselves are sometimes not the best in terms of biological activities including side effects, bioavailability, natural abundance and stability. Therefore, new

The author declares no conflict of interest. derivatives should be prepared on the basis of structural features of natural products by changing functionalities or even basic skeletons to eliminate such undesirable factors. Such chemical modifications sometimes provide much better medicines than those provided by natural products. Again, in order to obtain a wide variety of derivatives of natural products, it is essential to establish efficient synthetic procedures for desired compounds.

In this review article, the synthesis of biologically active natural products on the basis of newly developed reactions is introduced.

2. Development of Novel Reactions and Their Applications to the Synthesis of Biologically Active Compounds

2.1 Kinetic Resolution of 2-Furylcarbinols under Sharpless Epoxidation Conditions and Its Application to the Synthesis of Bioactive Natural Products It is recognized that 2-furylcarbinols serve as versatile building blocks in the synthesis of highly oxygenated natural products, since the oxidative conversion of 2-furylcarbinols leading to the corresponding pyranones provides one of the most useful synthetic pathways to polyoxygenated natural products due to facile elaboration of the functionality of such pyranones with either nucleophiles or electrophiles in a regioselective and stereoselective manner as shown in Chart 1.

We have already applied this strategy to the stereoselective construction of steroidal side chains in which optically active 


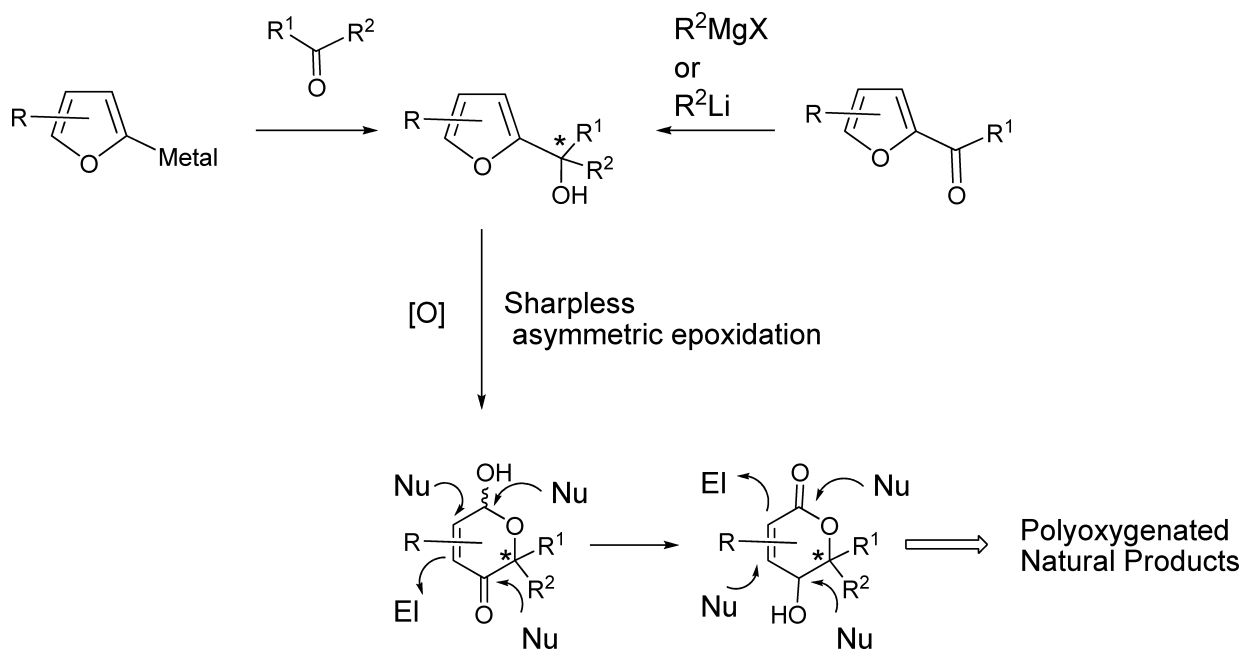

Chart 1. Conversion of 2-Furylcarbinols to Pyranones

20-oxo-steriod derivatives were employed as the starting materials. ${ }^{1)}$

In order to extend this synthetic strategy to its chiral version, we decided to apply Sharpless asymmetric epoxidation to the secondary 2-furylcarbinol for the induction of chirality, since 2-furylcarbinol is considered to be an extended allyl alcohol system. Based on extensive studies on kinetic resolution of secondary alcohols by Sharpless, it is reasonably assumed that the faster reacting 2-furylcarbinol would be oxidized preferentially to furnish the corresponding pyranone and the unchanged isomer should be recovered in an optically active form with an opposite optical rotation to the pyranone (Chart 2). (R)-2-Furylcarbinols were obtained by employing L-diisoproryl tartrate (L-DIPT), whereas the use of D-DIPT led to the formation of $(S)$-2-furylcarbinols with high enantiomeric purity (80-98\% ee).

By using the optically active 2-furylcarbinols obtained above as starting materials, a number of natural products, including (5R,6R)-6-acetoxyhexadecan-5-olide, ${ }^{2)} \quad(+)$-disparlure, ${ }^{2,3)}(-)$-canadensolide, ${ }^{4,5)}$ pumiliotoxin $251 \mathrm{D},{ }^{6}$ ) swainsonine, ${ }^{7)}(-)$-malyngolide, ${ }^{8)}$ goniothalamin, ${ }^{9)}$ argentilactone, ${ }^{9)}$ goniodiol ${ }^{10)}$ 9-deoxygoniopypyrone, ${ }^{10)}$ goniopypyrone, ${ }^{10)}$ (+)-goniofufurone, ${ }^{10)}(+)$-acetylgoniotriol, ${ }^{10)}(+)$-goniotriol, ${ }^{10)}(+)$-altholactone, ${ }^{10)}$ and monocrotalic acid, ${ }^{11)}$ have been synthesized in relatively short steps. ${ }^{12)}$ Application of this reaction using LDIPT to 2-furylcarbinol having an alkenyl moiety on the side

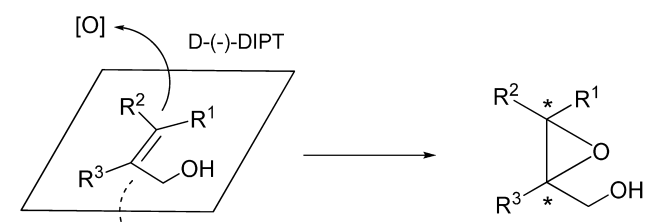

L-(+)-DIPT $\because[\mathrm{O}]$

$>90 \%$ ee

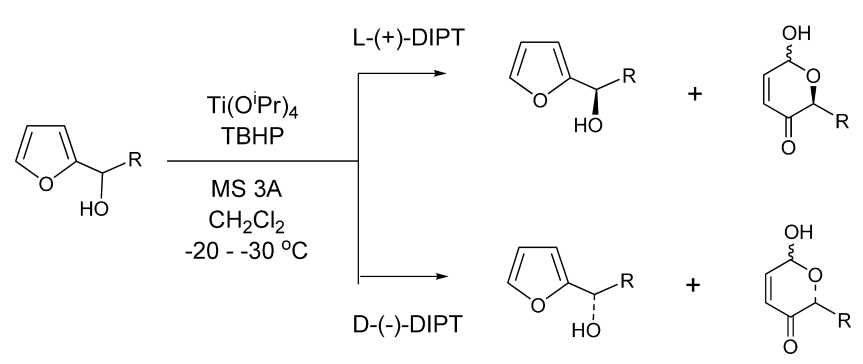

Chart 2. The Sharpless Epoxidation of 2-Furylcarbinols

chain resulted in formation of corresponding pyranone and $(R)$-furylcarbinol, respectively, suggesting that oxidation of the furyl double bond is faster than that of the alkenyl moiety on the side chain under those reaction conditions.

Based on those results, the synthesis of (+)-acetylphoma-

Dr. Toshio Honda is Professor of organic chemistry at Hoshi University. He was born in 1947 in Tokyo. He received his Ph. D. degree from Tohoku University in 1975 (Prof. Tetsuji Kametani). He started his academic career in 1972, right after he left a school during his Ph. D. course, as a research associate at the Pharmaceutical Institute, Tohoku University, and spent a postdoctoral year (April 1, 1976-December 31, 1978) at University of British Columbia, Canada (Prof. James P. Kutney). He became Lecturer at Tohoku University in 1980 and moved to Hoshi University in 1981. Since 1992, he has been a full professor at the same university. Prof. Honda received the Pharmaceutical Society of Japan Award for Young Scientists (1989), FIP Distinguished Scientist Award (2004), Kametani Award (2008), PSWC Research Achievement Award (2010) and the Pharmaceutical Society of Japan Award (2012). His research interests include the total synthesis of biologically active natural products, development of new synthetic methodology and strategy, and structure determination of

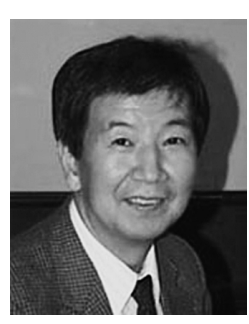

Toshio Honda natural products. He is also interested in working in the field of medicinal chemistry. 


$$
\begin{aligned}
& \text { 每 } \\
& \underbrace{\mathrm{O}_{\mathrm{PPTS}}^{\mathrm{O}}}_{\mathrm{O}} \\
& 3
\end{aligned}
$$

Chart 3. Synthesis of Acetylphomalactone

lactone (1), isolated from Aspergillus caespitosus as an antimicrobial metabolite having antitumor activity, was attempted as follows. ${ }^{13)}$ Kinetic resolution of 2-furylcarbinol (2) with tert-butyl hydroperoxide (TBHP) $(0.5 \mathrm{eq})$, a catalytic amount of L-DIPT (15 mol\%) and titanium tetraisopropoxide (10 mol\%) in $\mathrm{CH}_{2} \mathrm{Cl}_{2}$ in the presence of molecular sieves $3 \mathrm{~A}$ at $-30^{\circ} \mathrm{C}$ for $6 \mathrm{~h}$ afforded pyranone (3) in 33\% yield. After protection of the lactol with ethyl vinyl ether, the resulting major $\alpha$-anomer (4) was treated with $\mathrm{NaBH}_{4}$ to give an alcohol (5). Mitsunobu reaction of 5 using benzoic acid, followed by hydrolysis of the benzoate furnished a syn-alcohol (6). Acetylation of $\mathbf{6}$ and subsequent oxidation of acetate with $m$-chloroperbenzoic acid $(m-\mathrm{CPBA})$ and $\mathrm{BF}_{3} \cdot \mathrm{OEt}_{2}$ provided $(+)$-acetylphomalactone (1) (Chart 3). ${ }^{13)}$

As mentioned above, Sharpless kinetic resolution of 2-furylcarbinol bearing an alkenyl moiety on the side chain reflected the relative reactivity of both double bonds present in the molecule (Chart 4).

However, we found that the reactivity of the double bonds

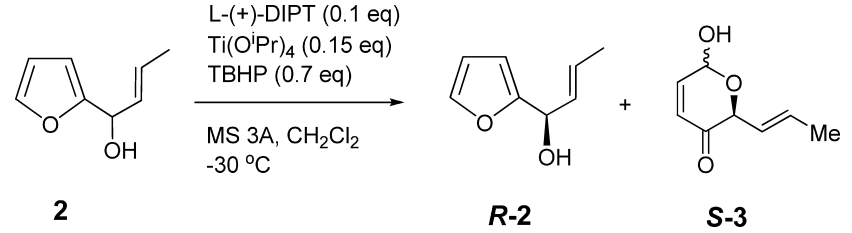

Chart 4. The Sharpless Epoxidation of (E)-(2-Furyl)but-2-en-1-ol
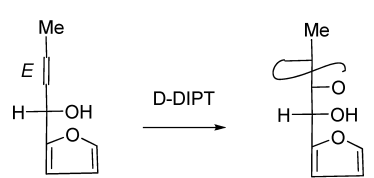

$\|$
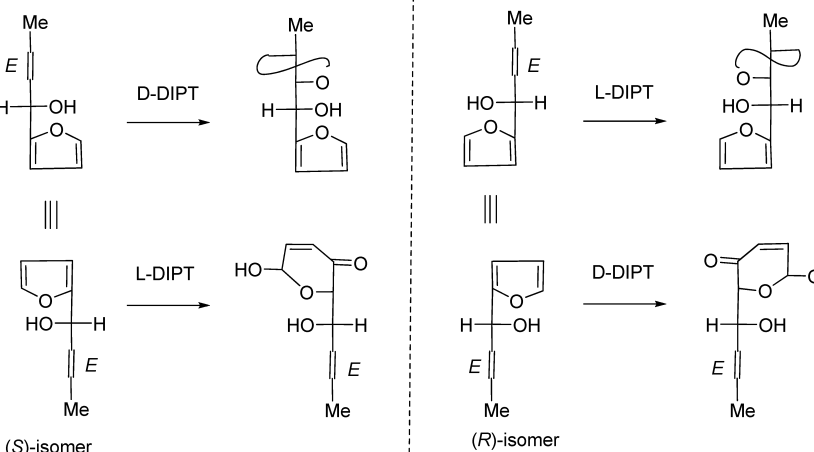

||

Chart 5. Fischer Projection of Sharpless Epoxidation of (E)-(2-Furyl)but-2-en-1-ol

of 2-furylcarbinol (2) varied with the chirality of DIPT employed in the reaction (Chart 5). ${ }^{14,15}$ )

Sharpless kinetic resolution of racemic 2-furylcarbinol (2) with 1.2 eq of TBHP in the presence of D-DIPT provided $(S)$ epoxide $(\boldsymbol{S}$-7) and $(R)$-pyranone $(\boldsymbol{R}-3)$ in 42 and $43 \%$ yields, respectively. Conversely, oxidation of racemic 2 with L-DIPT gave $(R)$-epoxide $(\boldsymbol{R}-\mathbf{7})$ and $(S)$-pyranone $(\boldsymbol{S}$-3) in 41 and $41 \%$ yields, respectively. It should be noted that none of the

Table 1. Sharpless Epoxidation of (E)-(2-Furyl)but-2-en-1-ol ${ }^{a)}$

Entry

a) All reactions were carried out at $-20^{\circ} \mathrm{C}$ with $\mathrm{Ti}\left(\mathrm{O}^{i} \mathrm{Pr}\right)_{4}(25 \mathrm{~mol} \%)$, DIPT $(30 \mathrm{~mol} \%)$, and TBHP $(120 \mathrm{~mol} \%)$ in the presence of $\mathrm{CaH}$ and $\mathrm{MS} 3 \mathrm{~A}$ except for entry $\left.2 . b\right)$ $150 \mathrm{~mol} \%$ of TBHP was used. 
epoxide diastereoisomers was isolated, suggesting that the epoxidation proceeded in an entirely diastereofacial-selective manner. When epoxidation for the optically active $(\boldsymbol{S}-\mathbf{2})$ was carried out with 1.2 eq of TBHP in the presence of L-DIPT, $(\boldsymbol{S}-\mathbf{3})$, arising from oxidation of the more reactive furan double bond, was isolated in $85 \%$ yield, whereas oxidation of the optically active $(\boldsymbol{S}-\mathbf{2})$ employing D-DIPT resulted in the formation of $(\boldsymbol{S}-7)$ in $89 \%$ yield. These results clearly indicated that the furan double bond of 2-furylcarbinol (2) formed a matched pair with the titanium L-DIPT complex, resulting in the formation of $(\boldsymbol{S}-3)$. However, the use of D-DIPT resulted in almost exclusive epoxidation of the alkenyl double bond, indicating that the alkenyl double bond of $\boldsymbol{S}-\mathbf{2}$ formed a matched pair with the titanium D-DIPT complex (Table 1).

By application of this methodology to natural product synthesis, synthesis of the antitumor antibiotic asperlin (8), isolated from Aspergillus nidulans, was investigated. The epoxyalcohol $(\boldsymbol{S}$-7) was oxidized with $N$-bromosuccinimide (NBS) in aqueous tetrahydrofuran (THF) to give the corresponding pyranone (9), which, on treatment with ethyl vinyl ether and pyridinium $p$-toluenesulfonate (PPTS), afforded pyranones (10 and 11) in 60 and 27\% yields, respectively. $\mathrm{NaBH}_{4}$ reduction of the major $\alpha$-anomer (10) in the presence of cerium chloride gave $\alpha$-alcohol (12) and $\beta$-alcohol (13) in 90 and $9 \%$ yields, respectively. The $\alpha$-alcohol (12) was easily converted to $\beta$-alcohol (13) under Mitsunobu reaction conditions followed by hydrolysis of the corresponding benzoate. After acetylation of $\mathbf{1 3}$ with acetic anhydride, hydrolysis of the resulting acetate with aqueous acetic acid and subsequent oxidation of the lactol with pyridinium chlorochromate (PCC) furnished asperlin (8) (Chart 6). ${ }^{14)}$

To the best of our knowledge, this is the first example of Sharpless epoxidation of the unsymmetrical divinylcarbinol leading to the formation of epoxide on a less reactive double bond in a region- and diastereofacial-selective manner.

Another example of a successful application of this methodology is the synthesis of $(11 S, 12 S, 13 S)-(9 Z, 15 Z)-$ and $(11 R, 12 S, 13 S)-(9 Z, 15 Z)-11$-hydroxy-12,13-epoxy octadecadienoic acids, self-defensive substances against rice blast disease. $^{16)}$ Addition of the lithium salt of 10-tert-butyldimethylsiloxy-1-decyne to aldehyde (15), readily accessible from (3Z)-hex-3-enal, gave alcohol, which was further converted to acetate (16). After removal of the silyl group, the resulting primary alcohol was oxidized to acid by successive oxidation with Dess-Martin periodinane reagent and sodium chlorite. Esterification of the acid with iodomethane and potassium carbonate afforded ester, which was further converted into triethylsilyl ether (17) by two steps involving methanolysis and silylation with triethylsilyl chloride (TESCI). The formation of (Z)-olefin from silyl ether (17) was achieved in a usual manner by using a catalytic reduction with the Lindlar catalyst followed by deprotection of the silyl group with tetrabutylammonium fluoride (TBAF) to give a secondary alcohol (18). With the requisite starting unsymmetrical divinylcarbinol (18) available, a study was made of the best conditions for Sharpless asymmetric epoxidation to the desired epoxy-alcohol. The reaction of 18 with 0.4 eq of TBHP, 0.55 eq of L-(+)-DIET and 0.5 eq of $\operatorname{Ti}\left(\mathrm{O}^{i} \mathrm{Pr}\right)_{4}$ in dichloromethane in the presence of calcium hydride and molecular sieves $3 \mathrm{~A}$ at $-40^{\circ} \mathrm{C}$ gave epoxyalcohol (19) and the recovered $(R)$-secondary alcohol (20), in $33 \%$ and $57 \%$ yields, respectively. No other products including

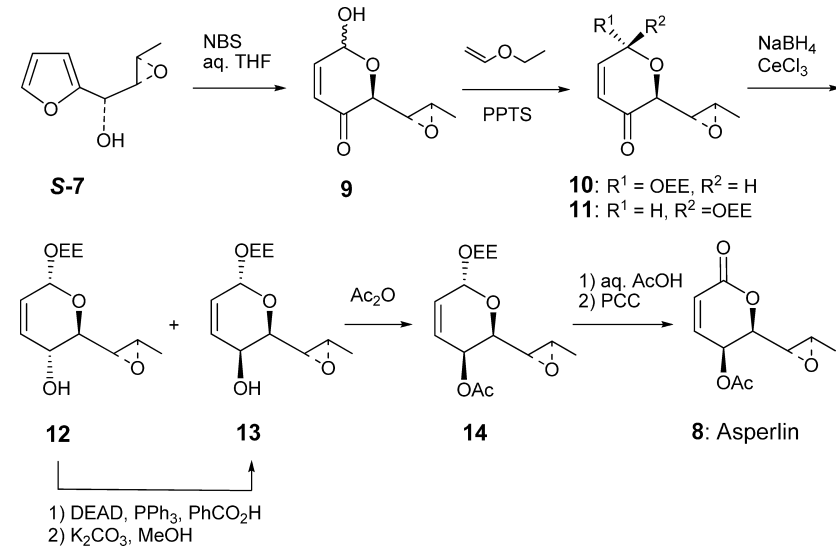

Chart 6. Synthesis of Asperlin

regioisomeric epoxide were isolated in this reaction. The spectroscopic data including specific rotation of the epoxide (19) were identical with those reported, ${ }^{16}$ ) suggesting its absolute configurations to be $11 \mathrm{~S}, 12 \mathrm{~S}$, and $13 \mathrm{~S}$. Its enantiomeric excess was also determined to be $94 \%$ by HPLC analysis with the chiral column CHIRALPAK AD. It should be noted again that the kinetic resolution and subsequent epoxidation of $\mathbf{1 8}$ under Sharpless asymmetric oxidation conditions proceeded in an entirely regio- and diastereoselective manner.

Finally, hydrolysis of the ester (19) with $0.5 \mathrm{~N}$ sodium hydroxide afforded the desired acid (21). (11R,12S,13S)-(9Z,15Z)11-Hydroxy-12,13-epoxoy octadecadienoic acid (22) was also synthesized from the epoxy-alcohol (19) by two steps, including Mitsunobu reaction with $p$-nitrobenzoic acid and hydrolysis of the resulting $p$-nitrobenzoate with lithium hydroxide (Chart 7). ${ }^{17)}$

The present work illustrates a further application of Sharpless asymmetric epoxidation of unsymmetrical divinylcarbinols to the synthesis of biologically active fatty acids with high optical purity.

2.2 Samarium Diiodide-Promoted Synthesis of Bioactive Natural Products Samarium diiodide $\left(\mathrm{SmI}_{2}\right)$, a mild and selective one-electron transfer reagent, has been utilized in a wide range of synthetic transformations. Among the various reactions developed for $\mathrm{SmI}_{2}$, we focused on its use for fragmentation reactions, and we established a regioselective carbon-carbon bond cleavage reaction of $\gamma$-halo carbonyl compounds and $\varepsilon$-halo- $\alpha, \beta$-unsaturated ester. Utilization of this strategy in the synthesis of various types of biologically active natural products has already been summarized as a review article (Chart 8). ${ }^{18)}$

In continuation of our work on the synthesis of biologically active natural products using $\mathrm{SmI}_{2}$, we were also interested in researching a general carbon-nitrogen bond cleavage reaction of $\alpha$-amino carbonyl compounds, and we were able to obtain successful results for systematic investigation of $\mathrm{SmI}_{2}$ promoted reductive carbon-nitrogen bond cleavage reaction. Since the application of this methodology to the synthesis of bioactive products has also been summarized as a review article (Chart 8), ${ }^{19)}$ we will introduce here our recent progress in the synthesis of bioactive natural products in which the newly developed samarium diiodide-promoted carbon-carbon bond forming reactions were involved as key reactions.

2.2.1 Synthesis of Stemoamide ${ }^{20)}$ Stemoamide (23), 

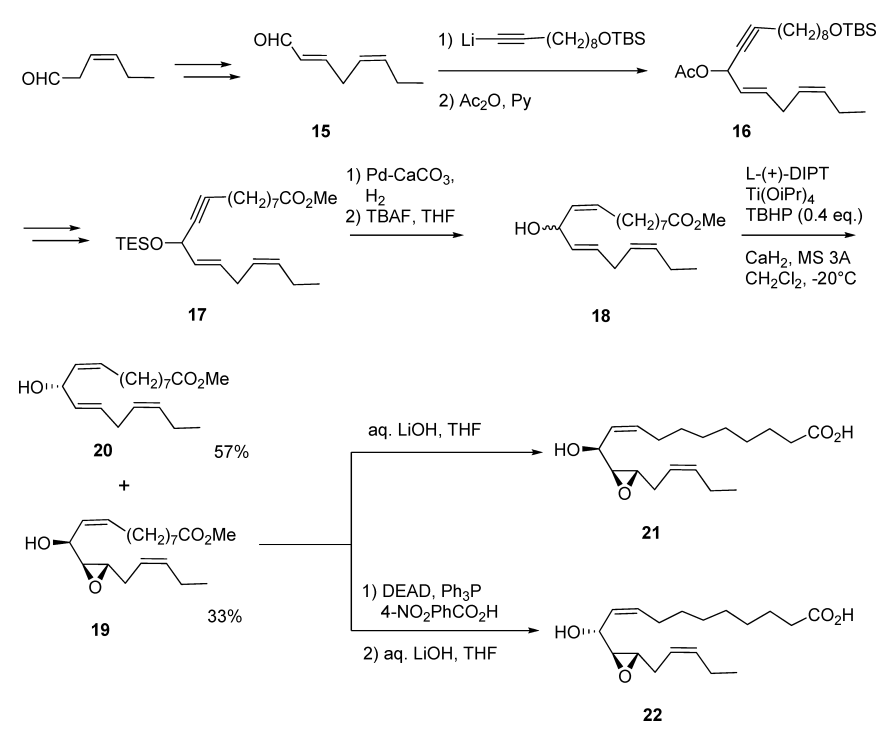

Chart 7. The Sharpless Epoxidation of the Unsymmetrical Divinylcarbinol

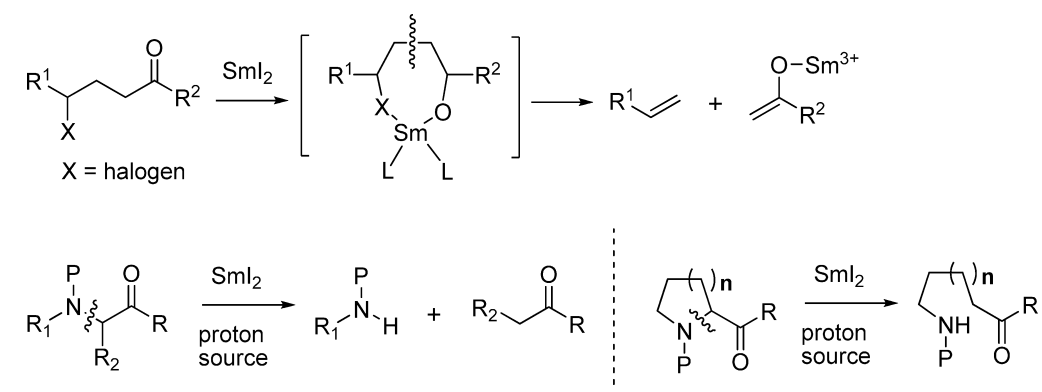

Chart 8. Regioselective C-C and C-N Bond Fragmentation Reactions with $\mathrm{SmI}_{2}$

isolated from the roots and rhizomes of Stemonaceous plants together with its related polycyclic alkaloids, stemonine, stenine and stemospironine, is the structurally simplest alkaloid among the Stemona class of natural products. The roots of Stemona tuberose Lour and related Stemona species (Stemonaceae) are used in Chinese traditional medicine as antitussive agents ${ }^{21}$ and also as insecticides and antihelminthics. ${ }^{22)}$ The structural feature of $\mathbf{2 3}$ was based on a $\gamma$-butyrolactam that forms part of a pyrrolo[1,2- $a]$ azepine ring system fused on a $\gamma$-butyrolactone ring with four contiguous stereogenic centers. Due to their interesting biological properties as well as their structural diversity, we are interested in developing an efficient synthetic route to this class of natural products.

The crucial step for the synthesis of $\mathbf{2 3}$ lies in the construction of a tricyclic ring system by controlling the stereogenic centers at the 1,3a, 10a and 10b positions. The most straightforward way to construct the desired stereochemistry at the 10a position must be the use of the known $(S)$-pyroglutamic acid derivative (24) as the starting material. Construction of a $\gamma$-butyrolactone fused on the seven-membered ring could be achieved by a carbon-carbon bond formation between $3 \mathrm{a}$ and $10 \mathrm{~b}$ by applying an intramolecular samarium diiodide-promoted conjugate addition of a ketyl radical generated in situ from a corresponding aldehyde to an $\alpha, \beta$-unsaturated ester. A stereoselective installation of a methyl group at the 1-position could also be achieved at the last stage of the synthesis. Our retrosynthetic route for $\mathbf{2 3}$ is depicted in Chart 9.

The requisite precursor (25) for $\mathrm{SmI}_{2}$-promoted cyclization was prepared from $\mathbf{2 4}$ by a 5 -step sequence in good yield. With the pivotal precursor in hand, we attempted a samarium diiodide-promoted carbon-carbon bond forming reaction via a 1,4-conjugate addition of a ketyl radical generated in situ from aldehyde (25) under various reaction conditions. First, an intramolecular coupling of aldehyde (25) was conducted with 5.0 eq of samarium diiodide in THF in the presence of $5.0 \mathrm{eq}$ of $\mathrm{MeOH}$ as the proton source at $0^{\circ} \mathrm{C}$ for $3 \mathrm{~h}$ to give an inseparable diastereoisomeric mixture of coupling products (26 and 27) in 60\% yield (Chart 10).

To confirm their structures unambiguously, the mixture was converted to butenolides (28 and 29), via the corresponding selenides, in $44 \%$ and $41 \%$ yields, respectively. Spectroscopic data of $\mathbf{2 8}$ including its specific optical rotation were comparable to those reported in the literature. ${ }^{23)}$ Further transformation of $\mathbf{2 8}$ to stemoamide (23) was achieved via the known $\gamma$-butyrolactone (30) by reduction of its carbon-carbon double bond with nickel chloride and sodium borohydride and subsequent stereoselective methylation of $\mathbf{3 0}$ with methyl iodide according to the literature procedure ${ }^{23)}$ (Chart 11).

In this synthesis, however, the expected distereoselectivity could not be obtained in the key cyclization step. Fortunately, when a samarium diiodide-promoted carbon-carbon bond forming reaction was carried out in the presence of hexamethylphosphoramide (HMPA), the desired lactone (30) was isolated in $55 \%$ yield, together with a trace amount of the diastereoisomer (32). Similar different reaction stereocontrol depending upon the reaction conditions was also observed by 


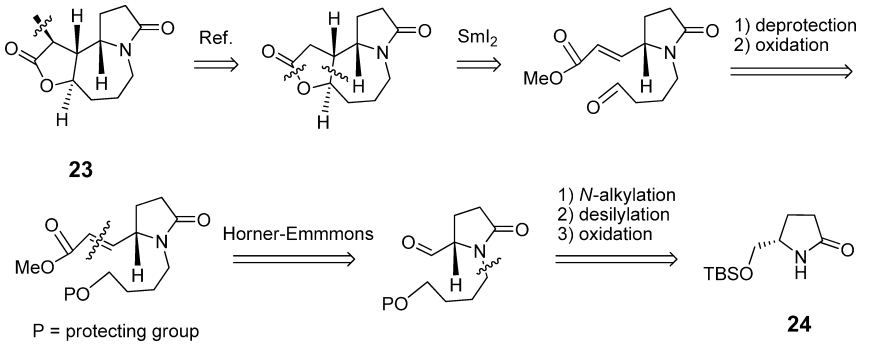

Chart 9. Retrosynthetic Route to Stemoamide

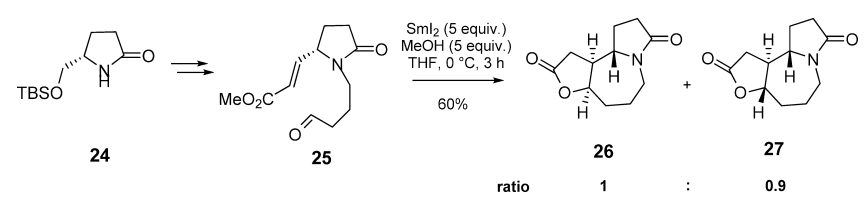

Chart 10. $\mathrm{SmI}_{2}$-Promoted 1,4-Conjugate Addition

several groups during samarium diiodide-promoted coupling reaction of carbonyl compounds in the presence or absence of HMPA. ${ }^{24-26)}$ For further investigation of the stereoselectivity, the $(Z)$-isomer of olefin (31) was subjected to the coupling. Again, the desired compound (30) was obtained by the reaction of $\mathbf{3 1}$ with samarium diiodide in the presence of HMPA in $39 \%$ yield, as the major coupling product. On the other hand, a similar reaction of $\mathbf{3 1}$ in the absence of HMPA furnished a mixture of $\mathbf{2 6}$ and $\mathbf{2 7}$ in moderate yield, with a ratio of $c a$. $1: 1$. These results clearly indicated that the stereochemistry at the carbon-carbon double bond did not affect the stereoselectivity of the product(s) for the samarium diiodide-promoted coupling and suggested that a chelation transition model usually observed in the absence of HMPA might not be involved in the coupling reaction in the presence of HMPA (Chart 12).

Thus, we were able to establish an efficient stereoselective synthesis of (-)-stemoamide starting from the known lactam, readily accessible from pyroglutamic acid, in eight steps and with $24 \%$ overall yield. Our synthesis features a samarium diiodide-promoted 7-exo-trig cyclization of a ketyl radical generated in situ from the corresponding aldehyde.

2.2.2 Synthesis of Sequosempervirin $A^{27)}$ Sequosempervirin A (33) was isolated from the dried and powdered branches and leaves of Sequoia sempervirens (Taxodiaceae) as the first naturally occurring norlignan compound. The structure of sequosempervirin A including its absolute configuration was determined to be (4R)-4-(4-hydroxybenzyl)spiro[4,5]dec-1-en-8-ol based on spectroscopic methods and its X-ray crystallographic analysis. ${ }^{28)}$ Acetone extracts of $S$. sempervirens exhibited antifungal activities towards Candida glabrata $\left(\mathrm{IC}_{50}=15.98 \mathrm{mg} / \mathrm{mL}\right)$, and both the acetone and $\mathrm{MeOH}$ extracts were found to inhibit the proteolytic activity of cathepsin B $\left(\mathrm{IC}_{50}=4.58,5.49 \mathrm{mg} / \mathrm{mL}\right.$, respectively ${ }^{.29}{ }^{2}$ The first synthesis of sequosempervirin A by Ghosh and Maity ${ }^{30)}$ involved an orthoester Claisen rearrangement and a ring-closing metathesis as the key reactions to construct the basic carbon framework. In their synthesis, however, deoxygenation at the 3-position (sequosempervirin A numbering) and also reduction of ketone at the 8-position resulted in a mixture of regio- and stereoisomeric compounds, respectively, providing the target compound as a racemic form in $2 \%$ overall yield in 13 steps. The crucial step for synthesis of sequosempervirin A obviously

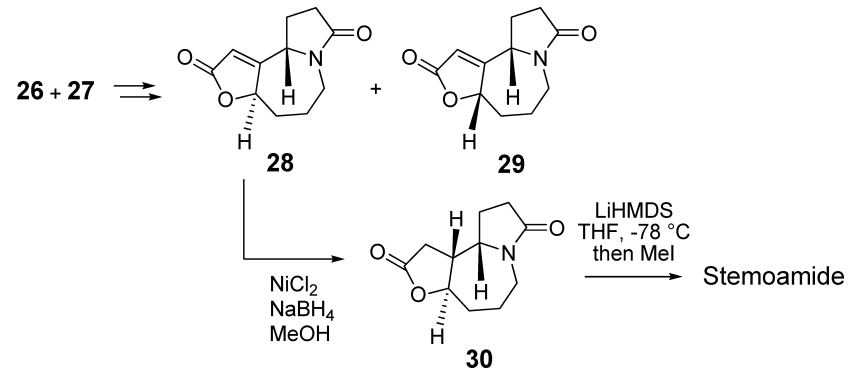

Chart 11. Synthesis of Stemoamide

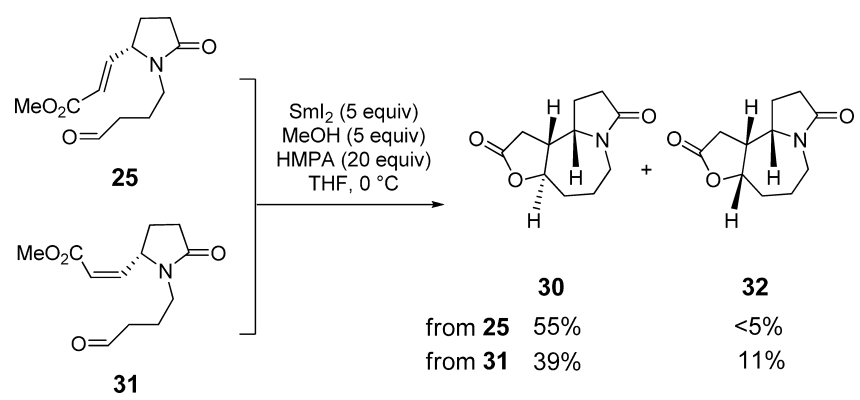

Chart 12. $\mathrm{SmI}_{2}$-Promoted Coupling Reaction of $(E)$ - and (Z)-Olefins

lies in the facile construction of a spiro[4,5]dec-1-en system by controlling the stereochemistry of the hydroxyl group at the 8-position, since this stereogenic center is located far from any functional groups in the target compound. Our retrosynthetic route for sequosempervirin $\mathrm{A}$ is depicted in Chart 13 .

Approaching the synthesis from a retrosynthetic perspective, we envisioned the following scheme: the target compound (33) would be derived from an alcohol $\mathbf{A}$ by employing a hydroxyl group-directed hygrogenation to control the stereochemistry at the 4-position and a subsequent dehydration. A benzylidene derivative A would be prepared from a cyclopentanone derivative $\mathbf{B}$ by installation of a benzyl moiety. Compound $\mathbf{B}$ would be accessible from a bicyclic lactone $\mathbf{C}$ via a samarium diiodide-promoted Barbier-type reaction. A lactonic halide $\mathbf{C}$ would be obtained from a 4-oxocyclohexane-1,1dicarboxylate $\mathbf{E}$ via a bicylic lactone $\mathbf{D}$.

A principal advantage offered by Chart 13 is the ready construction of the spiro[4,5]decane ring system with control of the stereochemistry of the hydroxyl group at the 8-position via a samarium diiodide-promoted Barbier-type reaction of a bicyclic compound $\mathbf{C}$ in one step.

The precursor (38) for a samarium diiodide-promoted Barbier-type reaction was prepared from 4-oxocyclohexanone-1,1dicarboxylate via the acid (35), the enone (36) and the chloride (37).

With the requisite starting material available, a study was carried out to find the best conditions for a samarium diiodide-promoted Barbier-type reaction of $\mathbf{3 8}$, and we found that nickel(II) iodide was the best additive ${ }^{31)}$ for this conversion to furnish the desired product in high yield. It is noteworthy that the samarium diiodide-promoted Barbier-type reaction of $\mathbf{3 8}$ led to the construction of a spiro[4,5]decane ring system, in which the hydroxyl group at the 8-position was fixed as only one diastereoisomeric form.

To synthesize the target compound, a stereoselective installation of a benzyl moiety to the position at the carbonyl group 

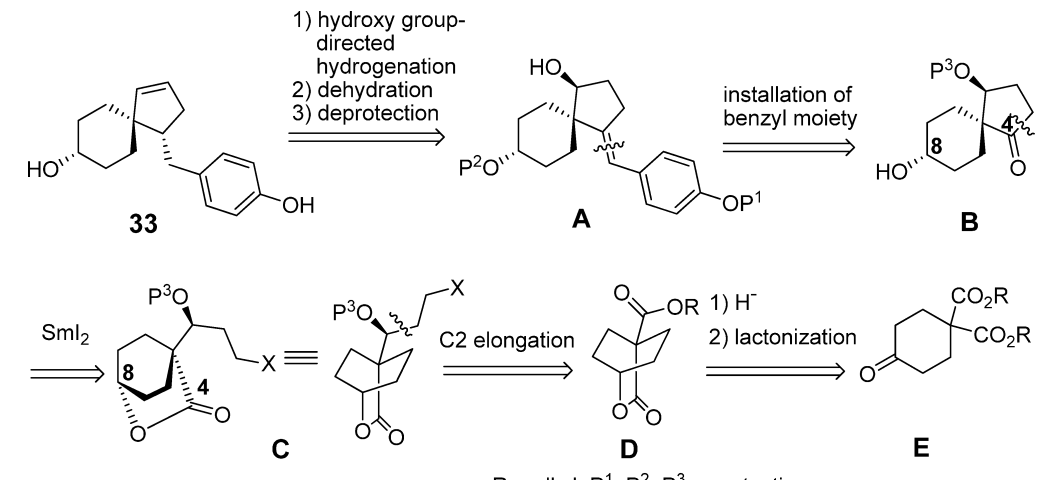

Chart 13. Retrosynthetic Analysis for Sequosempervirin A
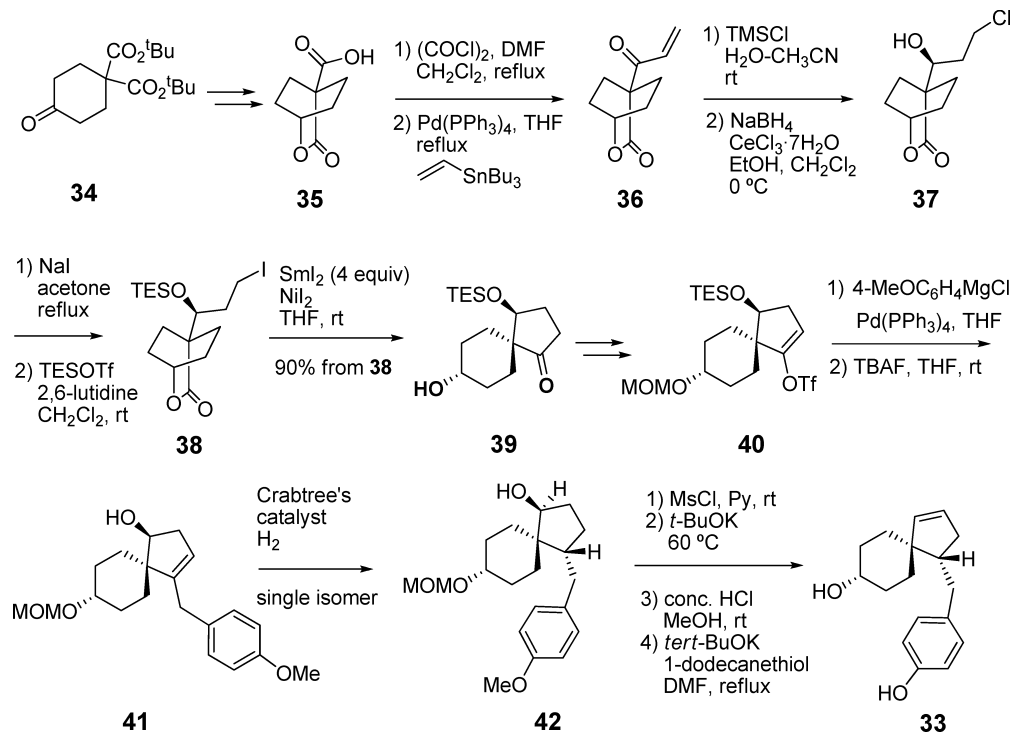

Chart 14. Synthesis of Racemic Sequosempervirin A

of 39 would be required. After various attempts, we found that a coupling reaction of triflate (40) with $p$-methoxybenzylmagnesium chloride in the presence of a palladium catalyst afforded a cyclopentenone derivative in good yield, which was further transformed to an aromatic compound (41) on treatment with TBAF. The stereochemistry at the 4-position was successfully controlled by employing a hydroxyl groupdirected hygrogenation with Crabtree's catalyst ${ }^{32)}$ to give cyclopentanol (42) as a single stereoisomer.

By establishing a synthetic route to the basic skeleton of the natural product with the desired stereochemistries, we completed the synthesis of sequosempervirin A as follows. Dehydration of the secondary hydroxyl group was achieved by steps involving mesylation of $\mathbf{4 2}$ followed by elimination of mesylate to provide the cyclopentene derivative. Finally, sequential removal of the protecting groups of the cyclopentene on treatment with conc. hydrochloric acid and potassium 1-dodecanethiolate afforded racemic sequosempervirin A (33) (Chart 14).

To accomplish the total synthesis of the optically active sequosempervirin $\mathrm{A}$, an asymmetric reduction of the prochiral ketone (43), derived from alcohol 41 by Dess-Martin periodinane oxidation, was exploited. Treatment of 43 with $(R)$-MeCBS and $\mathrm{BH}_{3}$-THF complex ${ }^{33,34)}$ in THF at $-20^{\circ} \mathrm{C}$ afforded chiral 41 with 91\% ee (Chart 15).

The absolute configuration of the newly generated chiral center was assumed to be $(S)$ on the basis of a previous systematic work. ${ }^{29)}$ Conversion of chiral 41 to natural 33 was achieved by adopting the same procedure as that described for the synthesis of racemic 33. The spectroscopic data of chiral compound $\mathbf{3 3}$ were identical with those of the racemate, but the sign of the optical rotation was opposite to the reported value for the natural product. To solve this confusion stemming from the different optical rotation values, we decided to determine the absolute configuration of our synthesized compound by X-ray analysis, and the results of X-ray analysis clearly showed that the synthesized compound has an $(R)$ configuration at the 4-position. These results indicated that the original assignment ${ }^{24)}$ for the absolute configuration of the natural product was not correct, and it should be revised to (4S)-4-(4-hydroxy-benzyl)spiro[4,5]dec-1-en-8-ol, an enantiomer of 33.

2.2.3 Diastereoselective Syntheses of Functionalized Five-Membered Carbocycles and Heterocycles by an $\mathrm{SmI}_{2}-$ Promoted Intramolecular Coupling of Bromoalkynes with $\boldsymbol{\alpha}, \boldsymbol{\beta}$-Unsaturated Esters $^{35)}$ The increasing interest in the development of new methodologies for selective syntheses of functionalized small- and medium-sized cyclic compounds 
with control of relative and absolute configuration lies in both the pharmacological applications of many of these cores and the presence of these skeletons in biologically relevant compounds including natural products. An intramolecular coupling reaction of alkynes with activated alkenes provides one of most promising routes to furnish functionalized cyclic compounds. For this purpose, transition-metal-mediated carbon-carbon bond forming reactions of alkynes with $\alpha, \beta$ unsaturated carbonyl compounds using $\mathrm{Rh}, \mathrm{Pd}, \mathrm{Co}, \mathrm{Ni}$, and Ti-complexes remain as outstanding methods among the most important for the construction of five-membered cyclic compounds.

An intramolecular samarium diiodide-promoted coupling of aldehydes or ketones with $\alpha, \beta$-unsaturated carbonyl compounds via a conjugate addition of ketyl radicals generated in situ is a well-established carbon-carbon bond forming reaction to give the corresponding cyclization products. Although a similar reaction of alkynes with $\alpha, \beta$-unsaturated carbonyl compounds has also been recognized as a general route to five-membered compounds by Moloney, ${ }^{36,37)}$ relatively low chemical yields as well as poor diastereoselectivities were observed in these carbon-carbon bond forming reactions, especially in the case of the $\alpha, \beta$-unsaturated ester due to its low reactivity as shown in Chart 16 .

This report prompted us to investigate a general and efficient samarium diiodide-promoted intramolecular coupling reaction of alkynes with $\alpha, \beta$-unsaturated esters leading to functionalized cyclic products with high stereoselectivity under mild reaction conditions.

We thought that the installation of a halogen at the terminus alkyne moiety might enhance the coupling of alkynes with $\alpha, \beta$-unsaturated carbonyl compounds, since we noted in advance that a samarium metal is able to coordinate with both a halogen and an ester oxygen, and the formation of relatively rigid structures might facilitate the reactivity of the vinylogous esters. Moreover, if the bromine atom remained untouched during the reaction, the resulting vinyl bromide would be a suitable intermediate for further chemical modification to highly substituted carbocycles or heterocycles (Chart 17).

Thus, we investigated a samarium diiodide-promoted intramolecular cyclization of bromoalkynes with $\alpha, \beta$-unsaturated esters, and we disclose herein an unprecedented coupling reaction leading to the corresponding five-membered cyclization products with high diastereoselectivities in excellent yields.

First, the reaction of 1-ethyl 4,4-dimethyl (1E)-7-bromohept-1-en-6-yne-1,4,4-tricarboxylate (44a) with samarium diiodide (3 eq) in THF was carried out, but, unfortunately, none of the cyclized product (45a) was isolated (Table 2, entry 6). On the other hand, a similar reaction in the presence of HMPA as an additive afforded the desired product (45a), in 64\% yield, in which the bromine atom remained on the exo-methylene moiety (Table 2, entry 1). By careful investigation of the reaction conditions for this conversion, we found that the presence of a proton source gave the cyclopentanes in good yields. As can be seen in Table 2, almost all of the proton sources are effective for this coupling. Among them, the use of hexafluoroisopropanol (HFIP) gave the desired product (45a) in high yield as the sole product.

To extend the scope of this carbon-carbon bond formation, synthesis of oxygen- and nitrogen-heterocycles, often observed in various types of natural products as a core fragment, has

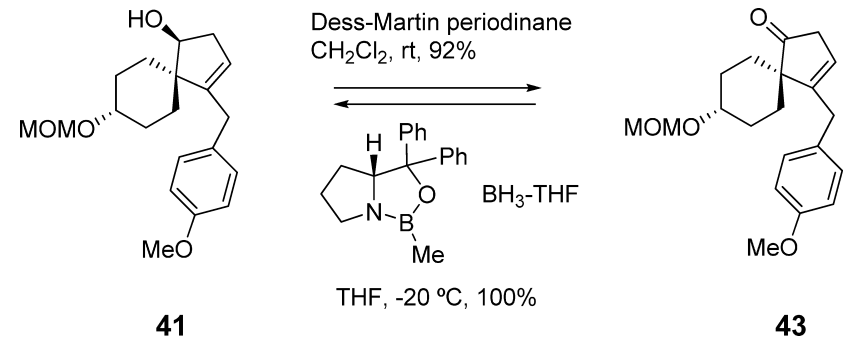

Chart 15. Chiral Induction for the Synthesis of Sequosempervirin A

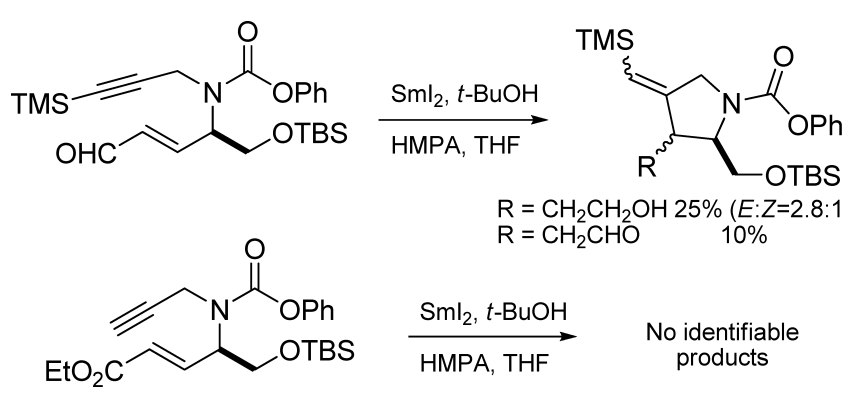

Chart 16. Previous Intramolecular Samarium Diiodide-Promoted Coupling of Alkynes with $\alpha, \beta$-Unsaturated Carbonyl Compounds

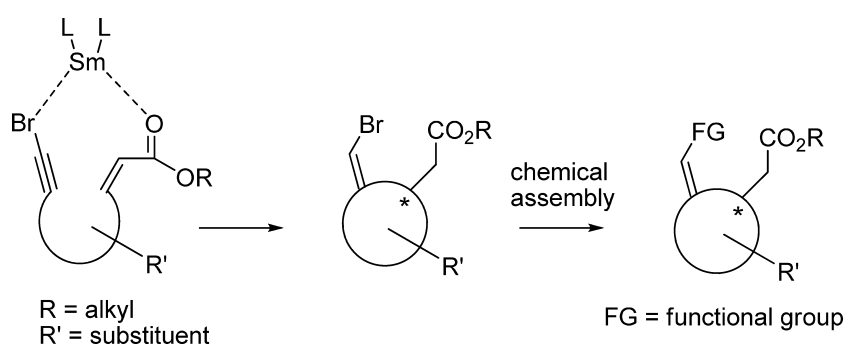

Chart 17. Proposed Intramolecular Coupling of Bromoalkynes with $\alpha, \beta$-Unsaturated Esters

been extensively investigated. The results obtained are summarized in Table 3.

Based on the results shown in Table 3, bulkiness of a substituent at the allylic position seems to play an important role in control of the stereochemistry at the 3-position of 2,3-substituted pyrrolidines (entries 5-9). By investigation of the ester group, higher diastereoselectivities were observed for methyl and ethyl esters than for the tert-butyl group, probably due to the absence of steric hindrance between the substituent at the 2-position and the ester (entry 6). Surprisingly, greatly improved trans: cis ratios of the products were observed when the coupling was carried out with the use of the corresponding (Z)-unsaturated esters as starting materials (entries 7 and 9). The preferential formation of 2,3-trans-pyrrolidines from $(E)$ $\alpha, \beta$-unsaturated esters would be realized based upon examination of molecular models of the transition states as depicted in Chart 18, where the transition state (A) was preferred to the transition state $(\mathbf{B})$ in terms of energetic and steric reasons.

The improved trans:cis ratio for $(Z)-\alpha, \beta$-unsaturated esters is consistent with the mechanistic proposal shown in Chart 18 , where severe steric repulsion was observed in the transition state (D) leading to 2,3-cis-isomer. Thus, the 2,3-transisomer would be a preferential product. In both cases, protonation occurred from the sterically less hindered side after 
carbon-carbon bond forming reaction to furnish the corresponding $(E)$-alkene isomers as major products.

A particular advantage of this reaction arises from the fact that the configuration at the 3-position of five-membered products can be controlled by reflection of the chirality of the substituent at the allylic position and the fact that chemical modification of the vinyl bromide newly elaborated in the products can provide highly functionalized five-membered compounds. To prove the potential utility of the bromine atom, a functionalization of vinyl bromide was attempted by palladium-catalyzed coupling reactions as shown in Chart 19.

Thus, we were able to establish a general and efficient samarium diiodide-promoted intramolecular coupling reaction of bromoalkynes with activated alkenes leading to highly functionalized five-membered carbocycles and heterocycles, in which the carbon-carbon bond forming reaction occurred with high diastereoselectivity under mild reaction conditions.

We believe that the newly developed synthetic strategy has a great potential for synthesis of a wide range of natural products bearing such a cyclic system.

2.3 Synthesis of Bioactive Natural Products by Means of Aromatic Oxidation with Hypervalent Iodine Reagents Hypervalent iodine reagents are useful synthetic tools due to their low toxicity, ready availability, and ease of handling. It is recognized that treatment of phenolic compounds with hypervalent iodine(III) reagents such as iodobenzene diacetate [PIDA; $\left.\mathrm{PhI}(\mathrm{OAc})_{2}\right]$ and iodobenzene di(trifluoroacetate) (PIFA) gives rise to a phenolic oxidation including oxidative coupling providing quinones, iodonium ylides, or coupling products depending on the structural properties of the substrates employed. The mechanism of phenol oxidation with hypervalent iodine reagents begins with the formation of an aryloxyiodonium(III) intermediate. Inter- or intramolecular nucleophilic attack then takes place either in one step or in two steps to provide the corresponding oxidation products.

2.3.1 Synthesis of a TAN1251 Series of Compounds ${ }^{38-40)}$ We decided to utilize this type of oxidation for the synthesis

Table 2. Preparation of Cyclopentane Derivatives by $\mathrm{SmI}_{2}$-Promoted Coupling of Bromoalkynes

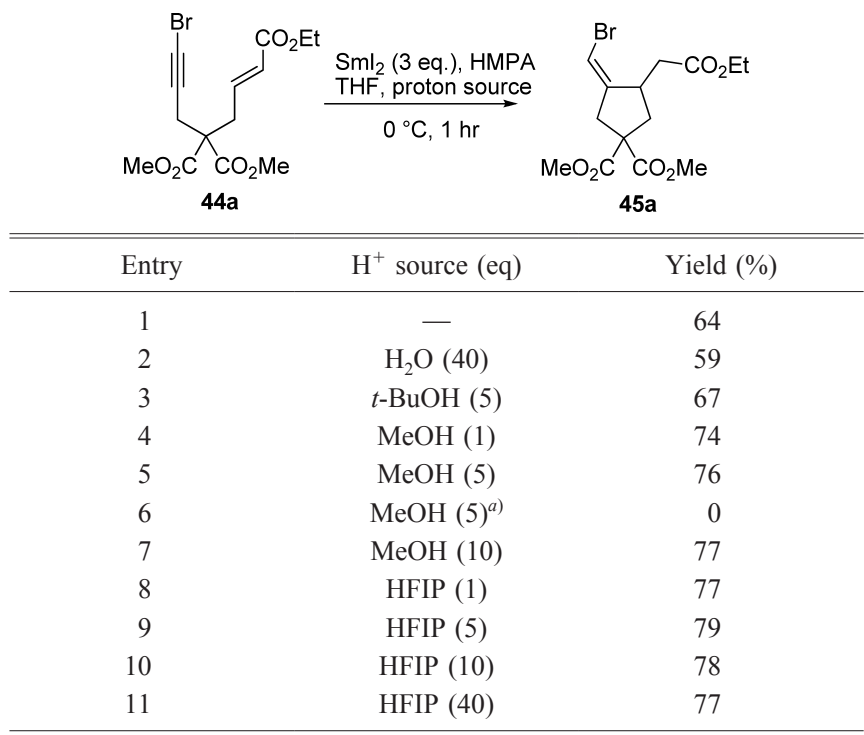

a) Starting material (73\%) and debromo-compound (18\%) were isolated in the absence of HMPA. of various types of biologically active natural products, and some of our syntheses are illustrated below. First, we investigated the synthesis of a TAN1251 series of compounds, in which a newly developed intramolecular nucleophilic attack of a secondary amine to an aryloxyiodonium(III) intermediate was involved as a key reaction.

TAN1251A (48), B (49), C (50) and D (51), having unique structural features with a spirocyclic cyclohexanone and a 1,4-diazabicyclo-[3.2.1]octane ring system, were isolated from Penicillium thomii RA-89 by Takeda Industries (Fig. 1). ${ }^{41)}$ TAN1251A is known as a selective muscarinic $\mathrm{M}_{1}$ subtype receptor antagonist. Moreover, TAN1251A and B exhibit cholinergic activity and inhibit acetylcholine-induced contraction of the guinea-pig ileum with $\mathrm{ED}_{50}$ values of 8.0 and $10.0 \mathrm{~nm}$, respectively. ${ }^{42)}$

In the chiral synthesis of TAN $1251 \mathrm{~A},{ }^{38,39)}$ we chose Ltyrosine and glycine as the starting materials, and aromatic oxidation of the secondary amine (53) with a hypervalent iodine reagent was employed, as the key reaction, to construct the desired spirocyclic carbon-nitrogen bond, as depicted in Chart 20.

In this synthesis, however, the benzylidene side chain was introduced at a later stage of its synthesis. Thus, we tried to develop a more effective synthetic path to those alkaloids, especially to TAN1251C and D. ${ }^{40)}$ For their synthesis, we decided to employ an aromatic oxidation of the dimeric L-tyrosine derivative having a desired benzyl side chain in its molecule. Using a similar synthetic procedure as that described above, the desired phenolic derivative (58) was synthesized from two molecules of L-tyrosine. Aromatic oxidation of $\mathbf{5 8}$ with PIDA in hexafluoroisopropanol as the solvent afforded the desired dienone (59) in the best yield (46\%). Reduction of 59 by using the same reaction conditions as those for the synthesis of TAN1251A followed by protection of the carbonyl group as its ethylene ketal and deprotection of the benzyl protecting group of the resulting amide gave a phenolic compound (60). Prenylation of $\mathbf{6 0}$ gave a prenyl ether $(\mathbf{6 1})$, which on reduction with lithium aluminun hydride afforded an amine (62). Finally, deprotection of the ketal group under an acidic condition furnished TAN1251D (51). ${ }^{40)}$ In order to accomplish the synthesis of TAN1251C, DIBAL reduction applied to the amide (61) in ether provided the desired enamine (63) in one step. Again, deprotection of the ketal group under an acidic condition afforded TAN1251C (50) (Chart 21).

Thus, we were able to disclose the facile synthesis of a TAN1251 series of compounds in optically pure forms starting from tyrosine and glycine or the dimeric tyrosine derivative. In these syntheses, an aromatic oxidation of phenolic secondary amines with a hypervalent reagent played an important role in construction of a problematic carbon-nitrogen bond. ${ }^{38-40)}$

2.3.2 Synthesis of Proaporphine Alkaloid via a Newly Developed Enamide-Phenol Coupling ${ }^{43}$ Proaporphine alkaloids have been recognized as biosynthetic precursors of aporphine alkaloids with a wide range of oxygenated substitution patterns. ${ }^{44)}$ Some of these alkaloids have been shown to exhibit interesting biological activities. For example, stepharine (64), isolated from Nelumbo nucifera and Stephania glabra, has antihypertensive activity without side effects such as $\alpha$ - or $\beta$-adrenergic blockade, sedative or depressant effects, or ganglion blockade, ${ }^{45}$ and also inhibits cholinesterase and 
Table 3. Preparation of Heterocycles by $\mathrm{SmI}_{2}$-Promoted Coupling of Bromoalkynes

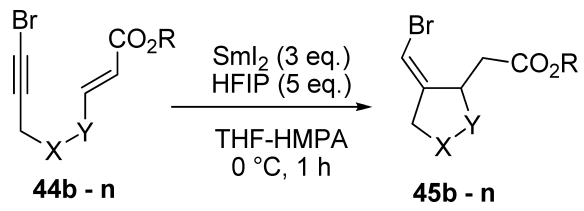

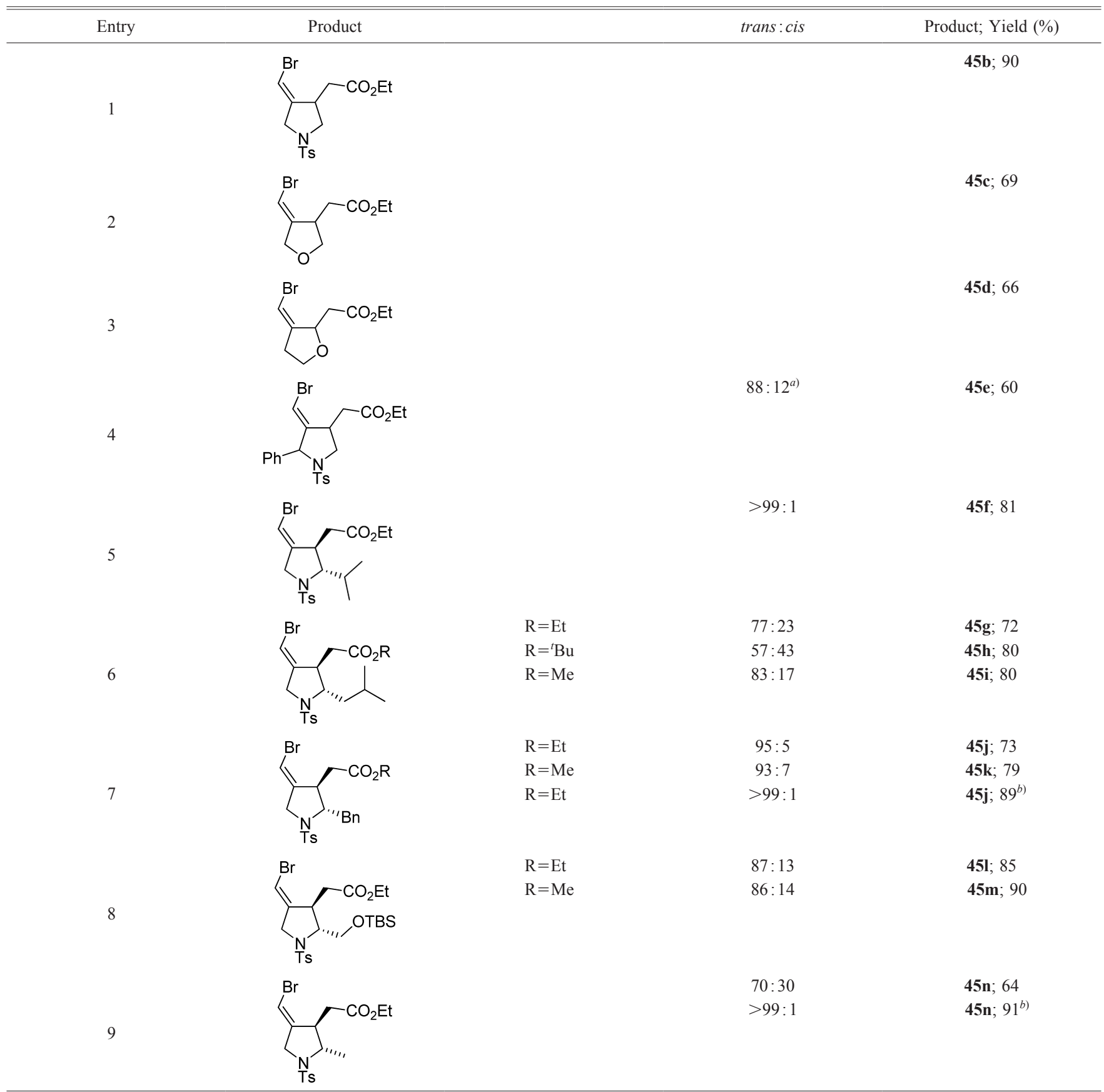

a) Relative stereochemistry between 2- and 4-positions is shown. b) (Z)-Unsaturated ester was employed as a material.

pseudocholinesterase in vitro. ${ }^{46)}$ Thus, we are interested in establishing an efficient synthetic methodology for these alkaloids, and we decided to exploit an aromatic oxidation of an enamide to construct the spirocyclic ring system present in the aporphine skeleton as a key reaction. Actually, it is of great interest for us to investigate an unprecedented carbon-carbon bond forming reaction between the para-position of a phenol group and an enamide-carbon.
The key intermadiate, enamide (69), was prepared from 3-bromo-4,5-dimethoxybenzaldehyde (65) by using $\mathrm{Su}-$ zuki-Miyaura coupling to provide a biaryl compound (66), Bischler-Napieralski cyclization of the acetamide (67) to give a 3,4-dihydroisoquinoline (68), and its acylation with trifluoroacetic anhydride, as key steps.

The aromatic oxidation of 69 with PIDA in trifluoroethanol at $0^{\circ} \mathrm{C}$, followed by sodium borohydride reduction of the 


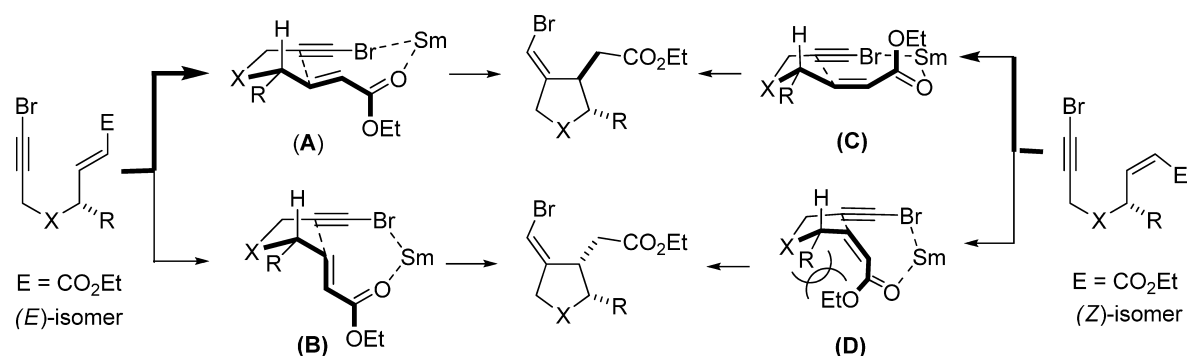

Chart 18. Proposed Reaction Mechanism for $\mathrm{SmI}_{2}$-Promoted Coupling of Bromoalkynes
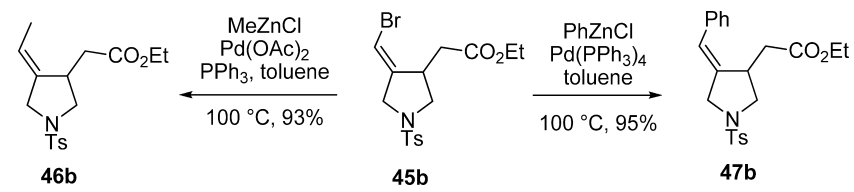

Chart 19. Chemical Assembly of Vinyl Bromide

resulting mixture, proceeded smoothly to give stepharine (64) in $90 \%$ yield as the sole product. $N$-Methylation of 64 with formalin under reductive reaction conditions afforded pronuciferine (70) in 79\% yield (Chart 22).

Thus, we were able to establish a novel and efficient synthesis of proaporphine alkaloids, in which an unprecedented carbon-carbon bond forming reaction between the para-position of a phenol group and an enamide-carbon was newly developed. This synthetic strategy is applicable to the synthesis of other types of isoquinoline and indole alkaloids.

2.3.3 Synthesis of a Spirocyclic Isoquinoline Alkaloid, Annosqualine $^{47)}$ Annosqualine (71), isolated from the stems of Annona squamosa in 2004, ${ }^{48)}$ is a novel isoquinoline alkaloid with an unprecedented skeleton bearing a spirocyclohexadienone function. Although the structure of $\mathbf{7 1}$ was elucidated spectroscopically, its synthesis and its biological activity have not been reported yet. For synthesis of this structurally unique alkaloid, we envisioned that an aromatic oxidation of phenolic enamide would provide the most straightforward route to construct the spirocyclohexadienone system as seen in the synthesis of proaporphine alkaloids.

Our synthesis was launched with preparation of the known aldehyde $(\mathbf{7 2})^{49)}$ by an alternative route in improved yield. Condensation of $\mathbf{7 2}$ with nitromethane in the usual manner afforded the corresponding nitrostyrene, which on reduction with lithium aluminum hydride followed by cetylation with

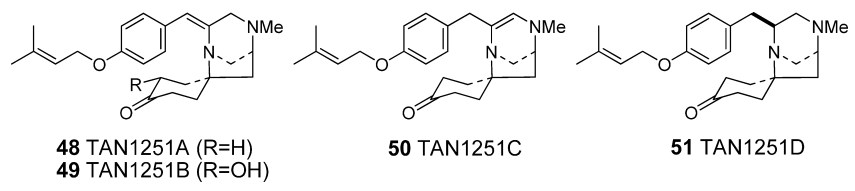

Fig. 1. The Structures of TAN1251 Series of Compounds

acetic anhydride gave an amide (73). After transformation of the benzyl ether of $\mathbf{7 3}$ to its ally ether $\mathbf{7 4}$, Bischler-Napieralski cylization with phosphoryl chloride in benzene gave 3,4-dihydroisoquinoline (75), which on treatment with acid chloride yielded an enamide (76). After treatment of $\mathbf{7 6}$ with TBAF in THF at room temperature, the resulting crude product, without purification, was reacted with PIDA in hexafluoroisopropanol at $0^{\circ} \mathrm{C}$ to successfully afford a spiro-enamide. Sodium borohydride reduction of the enamide in HFIP gave the reduction product (77) in $60 \%$ yield. The use of sodium cyanoborohydride as the reducing agent improved the formation of 77 to $86 \%$ yield. Finally, deprotection of the allyl group of 77 with a catalytic amount of bis(triphenylphosphine)palladium dichloride and tributyltin hydride ${ }^{50)}$ afforded $( \pm)$-annosqualine (71) (Chart 23).

2.4 Synthesis of (-)-Securinine ${ }^{51)}$ and (+)-Viroallosecurinine $^{52)}$ by Employing an Ring-Closing Metathesis (RCM) of the Corresponding Dienyne Among the various types of metathetic conversions, RCM is particularly relevant as a rapidly maturing tool for the formation of structurally diverse carbocyclic and heterocyclic compounds. RCM has also proven to be a valuable tool for constructing polycyclic compounds. One of the most promising starting materials for RCM is $1, \omega$-dines, which provides the corresponding cyclic compounds with almost any sizes; however, little attention has been given to the application of RCM to a dienyne in the

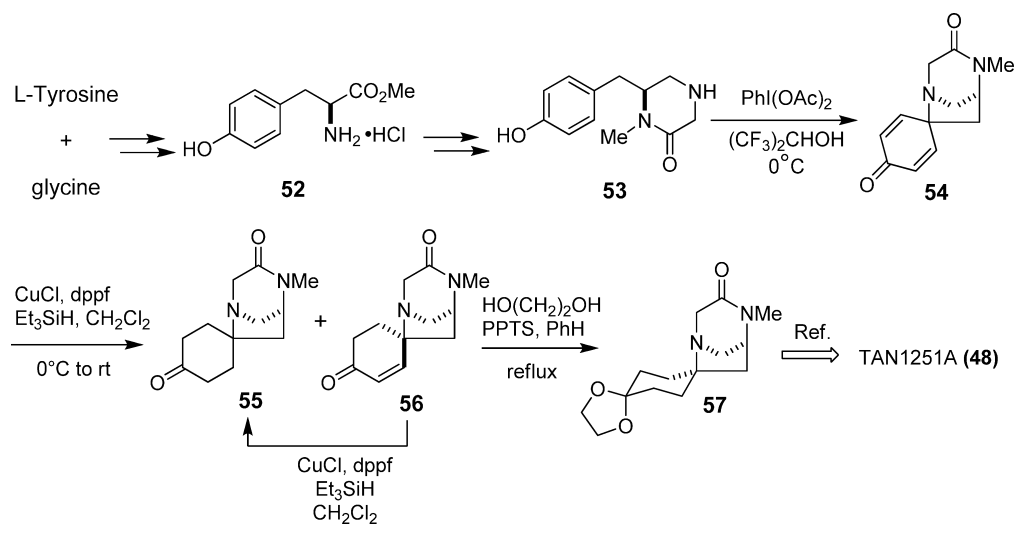

Chart 20. Synthesis of TAN1251A 

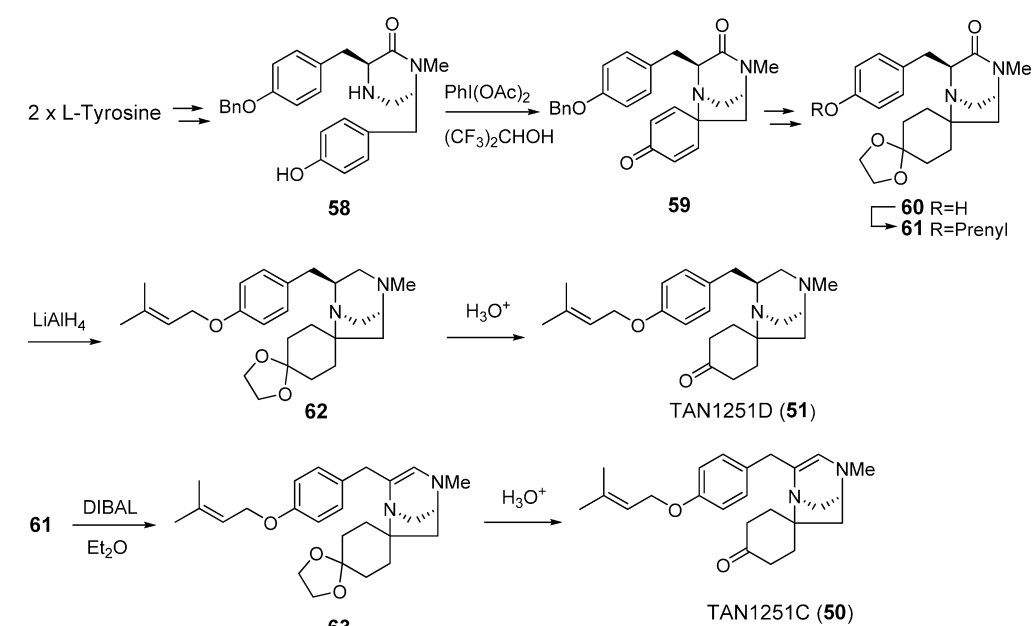

63

TAN1251C (50)

Chart 21. Synthesis of TAN1251C and D

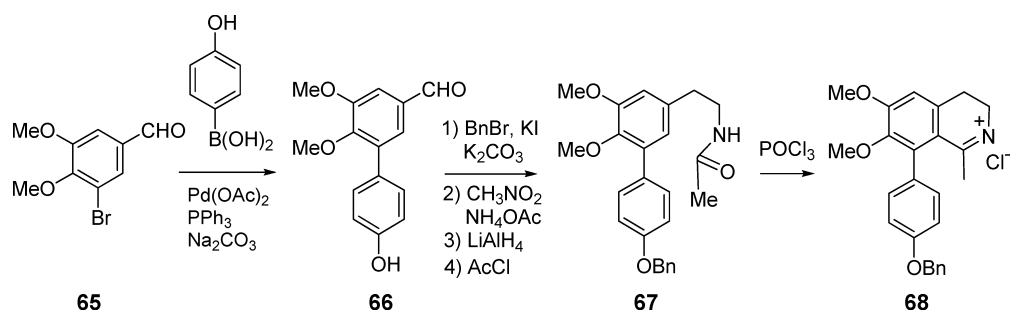

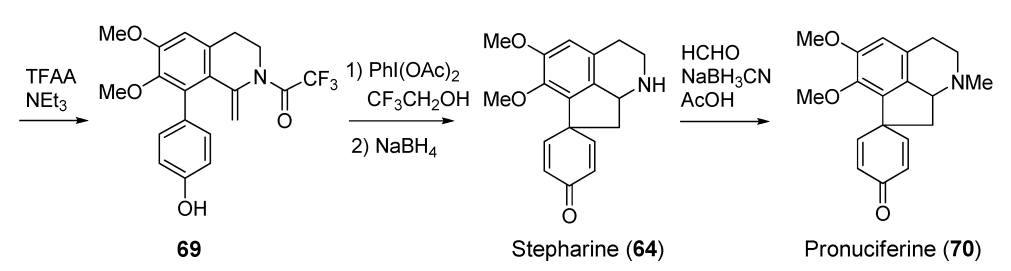

Chart 22. Synthesis of Stepharine and Pronuciferine

synthesis of natural products. Thus, we planned to utilize an intramolecular RCM of an enyne for the synthesis of biologically active alkaloids, securinine and viroallosecurinine, in optically pure forms.

Securinine (78), embodying the basic structural features of this class of alkaloids, was isolated from Securinega suffruticasa in 1956. ${ }^{53)}$ This alkaloid has been clinically used in Russia as a CNS-stimulating drug, ${ }^{54)}$ acting as a stereospecific antagonist at the GABA-binding site of the $\mathrm{GABA}_{\mathrm{A}}$-receptor complex. ${ }^{55)}$ Since it appears to be a fairly rigid molecule with a well-defined geometry, this alkaloid might aid in understanding the shape of the $\mathrm{GABA}_{\mathrm{A}}$ receptor site. ${ }^{55)}(+)$-Viroallosecurinine (79) was isolated from the leaves of Securinega virosa ${ }^{56,57)}$ Phyllanthus discoideus ${ }^{58)}$ and Breynia coronate ${ }^{59)}$ as a cytotoxic alkaloid together with its diastereomer (Fig. 2).

Viroallosecurinine (79) exhibited an minimum inhibitory concentration (MIC) of $0.48 \mu \mathrm{g} / \mathrm{mL}$ for Pseudomonas aeruginosa and Staphylococcus aureus; therefore, it was recognized to be a bactericidal since the yields of $\mathrm{MIC} / \mathrm{MBC}$ were less than $1 .^{60)}$ This alkaloid also showed significant cytotoxicity with an $\mathrm{ED}_{50}$ value of $0.9 \mu \mathrm{g} / \mathrm{mL}$ in in vitro $\mathrm{P}-338$ tissue culture cells. ${ }^{61)}$

Due to their attractive biological activities, we are interested in developing a general synthetic strategy for these alkaloids, and we thought that $(+)$-pipecolinic acid would be the most promising chiral starting material, since the stereogenic center of $(+)$-pipecolinic acid has the same configuration as those of the target compounds.

Thus, the optically active thioester $(\mathbf{8 2}),{ }^{62)}$ derived from (+)-pipecolinic acid, was treated with (3Z)-hexenylmagnesium bromide to give ketone (83). Addition of lithium trimethylsilylacetylide to $\mathbf{8 3}$ in the presence of cerium(III) chloride followed by deprotection of the silyl group with TBAF afforded a tertiary alcohol (84) as the sole product via the Felkin-Anh model.

Two RCM (ring closing metathesis) strategies were investigated for obtaining securinine. We first investigated RCM of the $\alpha, \beta$-unsaturated ester (85), derived from $\mathbf{8 4}$ by acylation with acryloyl chloride, using $1 \mathrm{~mol} \%$ loading of the nitroderivative of the Hoveyda catalyst. ${ }^{63-66)}$ However, the desired product could not be isolated under a range of reaction conditions, presumably due to the presence of a less reactive conjugated ester function. We, therefore, turned our attention to employing a more reactive allyl ether as the precursor for RCM. $O$-Allylation of $\mathbf{8 4}$ under an acidic condition employing allyl trichloroacetimidate and triflic acid afforded the desired product (86). RCM reaction of $\mathbf{8 6}$ using the same catalyst in methylene chloride gave the cyclization product, which on oxidation with chromium trioxide in the presence of 3,5-dimethylpyrazole provided lactone (87) (Chart 24). 

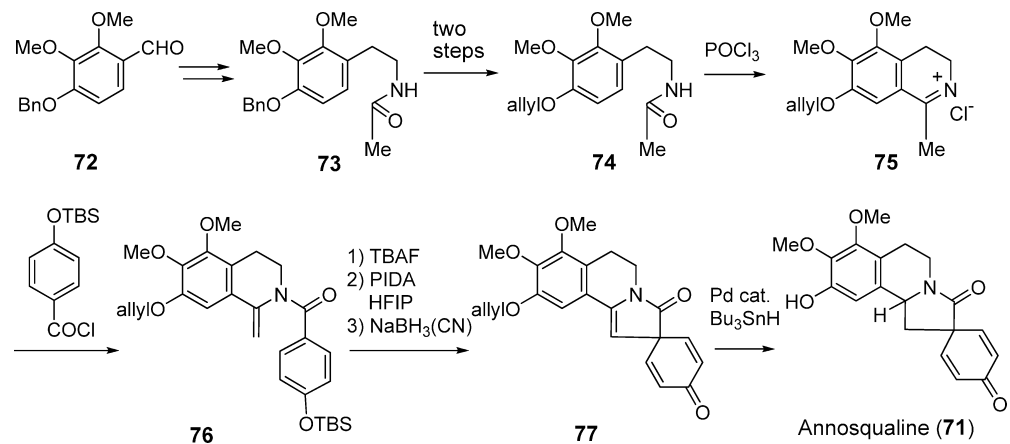

Chart 23. Synthesis of Annosqualine

Allylic bromination and subsequent deprotection of the Boc group with potassium carbonate furnished (-)-securinine (84). This is the first chiral synthesis of securinine.

In order to synthesize viroallosecurinine, introduction of an alkyne moiety to the ketone $(\mathbf{8 3})$ with stereoselectivity opposite to that in the case of synthesis of securinine would be required. Such stereoselective introduction was achieved via a chelation transition state by employing the corresponding $\mathrm{NH}$ compound as the starting material to give a tertiary alcohol $(\mathbf{8 8})$, as shown in Chart 25. O-Allylation of $\mathbf{8 8}$ with allyl tert-butylcarbonate and triphenylphosphine in the presence of a palladium catalyst ${ }^{67)}$ provided the desired allyl ether (89) in satisfactory yield. RCM of $\mathbf{8 9}$ afforded the cyclization product (90), which was further converted to $(+)$-viroallosecurinine (79) by employing the same reactions as those described for the synthesis of securinine (Chart 25).

2.5 Synthesis of Cassiarin A by Means of Simple Sequential Reactions ${ }^{68)}$ The genus Cassia is widely distributed in tropical and subtropical regions and is used in traditional folk medicine, particularly for treatment of periodic fever and malaria. ${ }^{69,70)}$ Recently, we have isolated two novel heteroaromatic alkaloids, cassiarin A (91) and cassiarin B (92), from the leaves of Cassia siamea (Leguminosae) (Fig. 3). ${ }^{71}$

Due to the unique structural features and also the strong antiplasmodial activity of cassiarin $\mathrm{A}$, we are interested in establishing a synthetic method for this alkaloid, which will hopefully be applicable to the synthesis of new potential antiplasmodial compounds. We envisaged that exploitation of sequential Sonogashira coupling for introducing alkyne groups to aromatic rings and subsequent 6-endo-dig cyclization of oxygen atoms to the resulting alkynes would be the
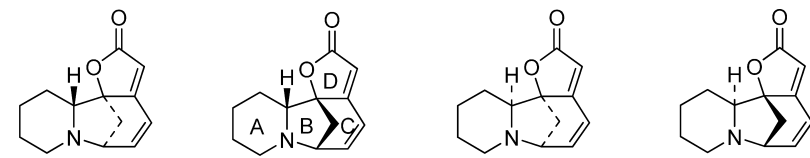

Securinine (78)

Viroallosecurinine (79) Allosecurinine (80)

Virosecurinine (81)

Fig. 2. The Structures of Securinega Alkaloids

most straightforward way to achieve the goal of constructing heteroaromatic skeletons. The known dihydroxy-ester $(\mathbf{9 3})^{72)}$ was converted to bismethoxymethyl ether (94). Sonogashira coupling of 94 with in situ generated propyne provided alkyne (95), which on hydrolysis with an aqueous base followed by acidification of the reaction mixture provided, upon standing, isocoumarine (96). Transformation of 96 to an isoquinolone derivative (97) was carried out by stirring with $28 \%$ ammonium hydroxide in $N, N$-dimethylformamide (DMF) at room temperature followed by heating at $80^{\circ} \mathrm{C}$ to facilitate cyclization of the keto-amide intermediate.

After conversion of the amide (97) to the corresponding triflate (98) with $N$-phenyl-bis(trifluoromethanesulfonimide) ${ }^{73)}$ in the presence of sodium hydride, Sonogashira coupling of $\mathbf{9 8}$ with in situ generated propyne gave alkyne (99) in 77\% yield. Finally, deprotection of methoxymethyl groups and 6-endo-dig cyclization were performed in one step by employing $10 \%$

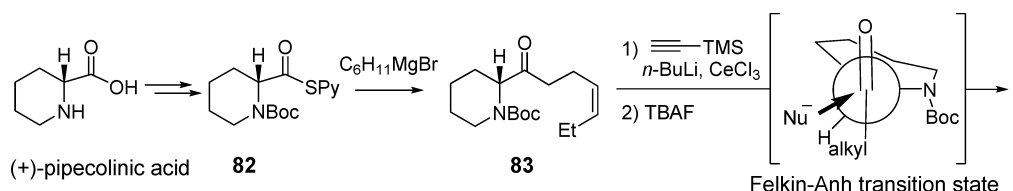

(+)-pipecolinic acid $\quad 82$

Felkin-Anh transition state

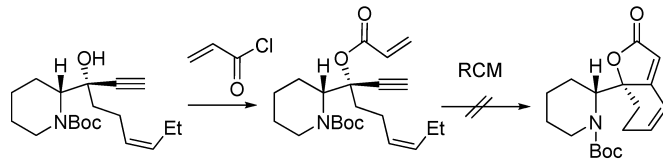

85

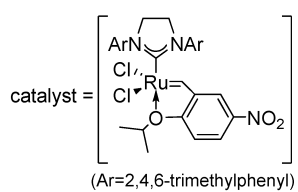

84
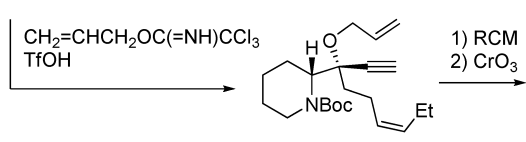

86

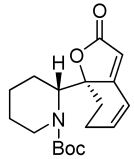

87

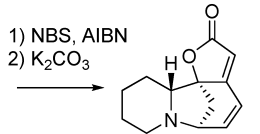

(-)-Securinine (78)

Chart 24. The First Chiral Synthesis of (-)-Securinine 


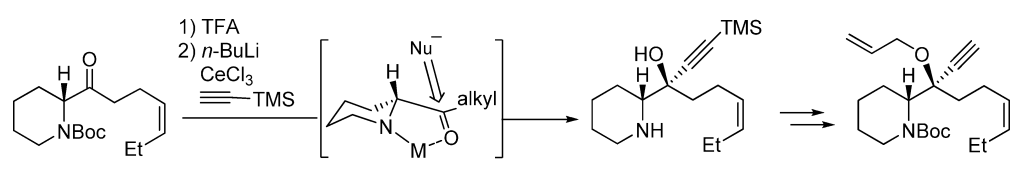

83

chelation-controlled addition

88

89

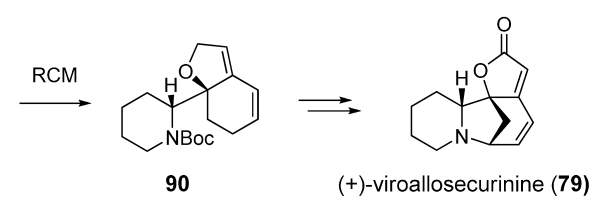

Chart 25. The First Chiral Synthesis of (+)-Viroallosecurinine

$\mathrm{HCl}$ solution in methanol to quantitatively give cassiarin A (91) (Chart 26).

Thus, we were able to establish a concise synthetic route for cassiarin A by employing Sonogashira coupling and 6-endodig cyclization as the key reactions. This is the first reported synthesis of cassiarin A. This synthesis gave the target compound in 51\% overall yield in seven steps from a readily accessible known starting material (93).

2.6 Development of Honda-Reformatsky Reaction ${ }^{74-76)}$ The Reformatsky reaction is a well-recognized carbon-carbon bond-forming reaction of an $\alpha$-halo ester with an aldehyde or a ketone in the presence of zinc metal to give a $\beta$-hydroxy ester. $^{77-79)}$ A particular advantage of this reaction stems from the fact that the site of reaction is strictly determined by the halogen moiety. This may be advantageously used for regioselective enolate formation in polycarbonyl compounds, which is difficult to achieve by base-induced proton abstraction. ${ }^{80-82)}$ To extend the scope of the Reformatsky reaction, various parameters have been extensively investigated. Since the reaction is initiated by insertion of zinc into the carbon-halogen bond, most efforts have been focused on the activation of zinc or the utilization of other metals to facilitate the insertion. Although little attention has been given to a catalytic version of this type of reaction, there is an interesting variant that utilized zinc and a catalytic amount of titanocene dichloride (Chart 27). ${ }^{83)}$

This report prompted us to try to establish an efficient and mild transition metal-catalyzed Reformatsky-type reaction.<smiles>CC1=Cc2cc(O)cc3cc(C)cc(c23)O1</smiles>

Cassiarin A (91)<smiles>CC(=O)CCCn1c(C)cc2cc(=O)cc3oc(C)cc1c23</smiles>

Cassiarin B (92)
Fig. 3. The Structures of Cassiarins A and B

After investigation of various transition metals, we found a new Reformatsky-type reaction promoted by rhodium catalysis and conducted under mild reaction conditions.

In an intermolecular version, aromatic and aliphatic aldehydes or ketones reacted smoothly with ethyl bromoacetate or ethyl 2-bromopropionate in the presence of Wilkinson's catalyst and diethylzinc to give $\beta$-hydroxy esters in moderate to good yields. It is noteworthy that no ethyl adduct was produced and that the reactions were usually completed within 5 min under the conditions shown in Table 4.

In the absence of $\mathrm{RhCl}\left(\mathrm{PPh}_{3}\right)_{3}$ or diethylzinc, recovery of the starting material was observed. This suggests that Rh(I) efficiently catalyzes the reaction. We next focused on the intramolecular reaction. As shown in Table 5, the reaction developed above also effected intramolecular carbon-carbon bond formation, as expected, providing secondary and tertiary cycloalkanols in good to excellent yields under similar reaction conditions. For the reactions forming five-membered rings<smiles>[R]Oc1cc([2H])c(C(=O)OC)c(I)c1</smiles>

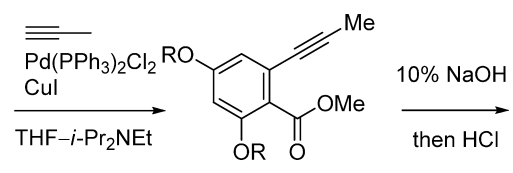
95<smiles>[R6]Oc1cc(O)c2c(=O)oc([N+](=O)[O-])cc2c1</smiles>

96

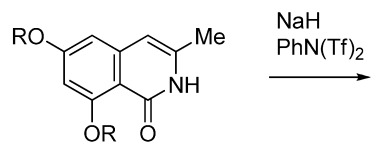

97<smiles>[R6]Oc1cc([2H])c2c(O)nc(C)cc2c1</smiles>

98

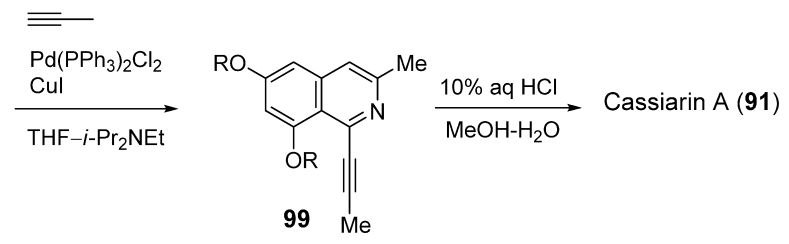

Chart 26. Synthesis of Cassiarin A 
(entries 1 and 2), high diastereoselectivities were observed, giving cis-hydroxy ester as the major product. This result is attributed to the sterically and electronically more favored rigid conformation of the transition state including zinc as depicted in Fig. $4{ }^{84)}$ On the other hand, in entries 3 and 4, reactions forming six-membered rings, the stereoselections were remarkably diminished. From the results obtained above, it is apparent that zinc also plays an important role in stereocontrol of the reaction as previously reported. ${ }^{84}$

Based on results of detailed mechanistic investigation of the ethylzinc enolate formation from 2-bromo-4,4-dimethyl3-pentanone and diethylzinc by Heathcock, ${ }^{85}$ a plausible mechanism, as depicted in Fig. 5, in which oxidative addition of $\alpha$-halo ester to $\mathrm{Rh}(\mathrm{I})$ initiates the reaction was proposed.

After formation of a rhodium(III) complex, transmetalation with diethylzinc produces ethylzinc enolate and $\mathrm{Rh}(\mathrm{I})$, by which the reaction could be catalyzed again. Nucleophilic addition of zinc enolate to a carbonyl compound would then afford zinc alkoxide, which upon hydrolysis should give $\beta$-hydroxy ester. Thus, we have developed a mild and efficient Reformatsky-type reaction catalyzed by $\mathrm{RhCl}\left(\mathrm{PPh}_{3}\right)_{3}$ and diethylzinc that can be conducted under mild reaction conditions.

By exploiting this methodology, achiral $\beta$-amino esters were synthesized in one pot from three components, amines, aldehydes and ethyl bromoacetate, under the rhodium-catalyzed Reformatsky-type reaction condition, in which complete diastereoselection was achieved in the nucleophilic addition step of ethyl bromoacetate to imines prepared in situ. As shown in Table 6 , the desired $\beta$-amino esters were obtained from both aromatic and aliphatic aldehydes and amines by one-pot preparation in moderate yields, probably depending on the stability of the imines formed in situ.

It is noteworthy that the addition reactions without the presence of Wilkinson's catalyst gave the desired products in the range of $10-20 \%$ yields with much longer reaction time (more than $2 \mathrm{~h}$ ). These results suggested that Wilkinson's catalyst improves the reactions in terms of yield and reaction time.

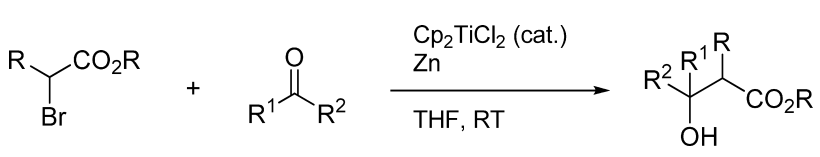

Chart 27. Titanocene Dichloride Catalyzed Reformatsky Reaction

Having developed a method for the preparation of racemic $\beta$-amino esters, in one pot, from three components, aldehydes, amines and ethyl bromoacetate, under rhodium-catalyzed reaction conditions, we next focused on the synthesis of optically pure $\beta$-amino esters. Among the various chiral auxiliaries reported in the literature, we chose the readily available benzyl ether of $(R)$-phenylglycinol.

Following the procedure developed above with the benzyl ether of $(R)$-phenylglycinol, the desired $\beta$-amino esters were obtained as single isomers as shown in Table 7 . With both aromatic and aliphatic aldehydes, desired $\beta$-amino esters were obtained in moderate to good yields without giving any diastereoisomers. The absolute configurations of the coupling products were unambiguously determined by comparison of

Table 5. Intramolecular Honda-Reformatsky Reaction

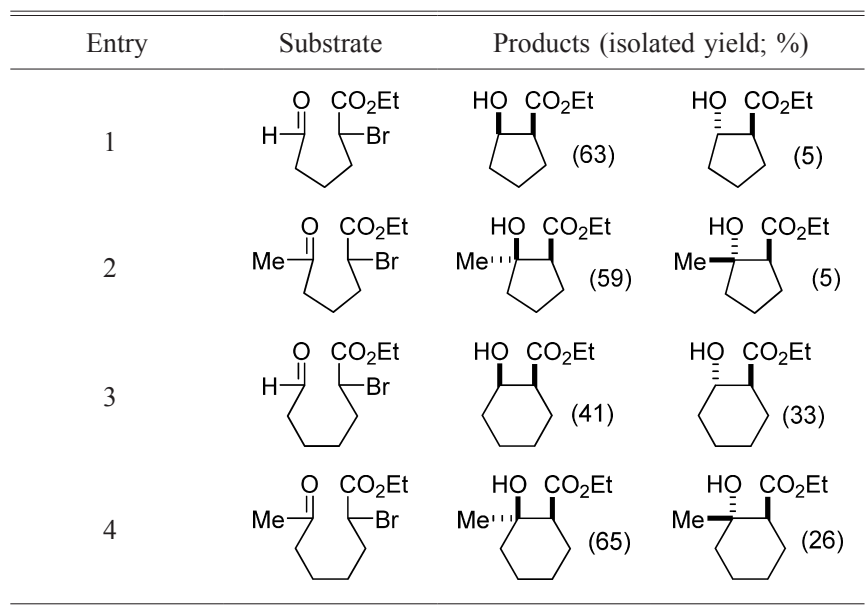

Table 4. Intermolecular Honda-Reformatsky Reaction

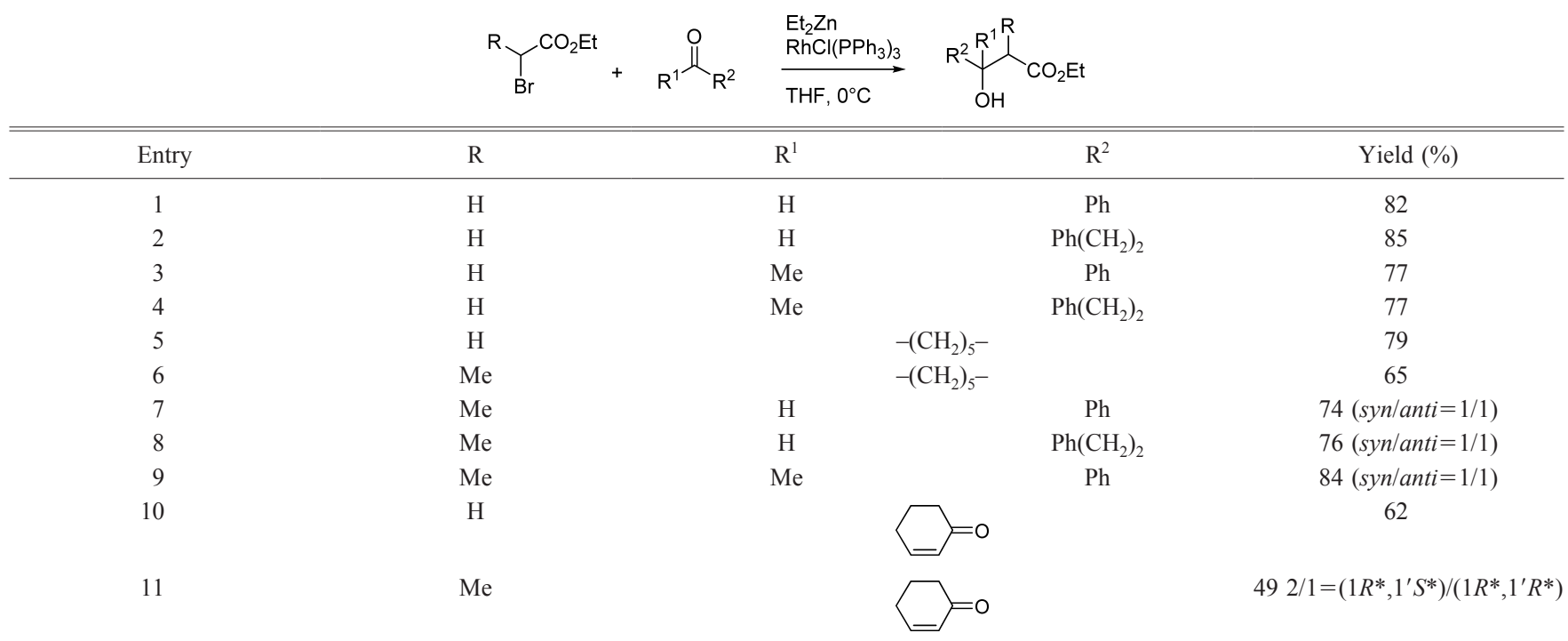

Representative procedure for intermolecular Reformatsky-type reaction: To a stirred solution of $\mathrm{RhCl}\left(\mathrm{PPh}_{3}\right)_{3}(5 \mathrm{~mol} \%)$ in THF at $0^{\circ} \mathrm{C}$ were added $\alpha$-halo ester, carbonyl compound, and a $c a .1 .0 \mathrm{M}$ hexane solution of $\mathrm{Et}_{2} \mathrm{Zn}(2.2 \mathrm{eq})$. After stirring for $5 \mathrm{~min}$ at $0^{\circ} \mathrm{C}$, saturated aqueous $\mathrm{NaHCO}_{3}$ was added. The reaction was filtered, and the filtrate was partitioned between $\mathrm{Et}_{2} \mathrm{O}$ and brine. The organic extract was dried $\left(\mathrm{Na}_{2} \mathrm{SO}_{4}\right)$, and the residue was purified by column chromatography on silica gel. 
Table 6. One-Pot Preparation of $\beta$-Amino Esters

\begin{tabular}{ll} 
Entry \\
\hline
\end{tabular}

Table 7. One-Pot Preparation of Chiral $\beta$-Amino Esters

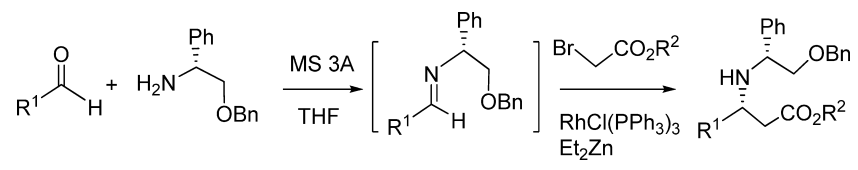

\begin{tabular}{cccc}
\hline \hline Entry & $\mathrm{R}^{1}$ & $\mathrm{R}^{2}$ & $\begin{array}{c}\text { Product (isolated } \\
\text { yield; \%) }\end{array}$ \\
\hline 1 & Ph & Et & 78 \\
2 & Isopropyl & Et & 70 \\
3 & Propyl & Et & 85 \\
4 & Propyl & $\mathrm{Me}$ & 76 \\
5 & Cyclohexyl & $\mathrm{Et}$ & 62 \\
\hline
\end{tabular}

the specific optical rotations of the products with those reported. Figure 6 with its transition state appears to best depict our experimental observations, where zinc enolates ${ }^{74)}$ attack from the sterically less hindered re face of the imines.

Further cleavage of the chiral auxiliary was best achieved by hydrogenolysis in the presence of Pearlman's catalyst under 4 atms of hydrogen in acetic acid or subsequent lead tetraacetate treatment of the debenzylation products.

Finally, $\beta$-amino esters and $\beta$-lactams were synthesized selectively from aldimines and ethyl bromoacetate by applying a simply modified rhodium-catalyzed Reformatsky-type reaction. ${ }^{76)}$ In the synthesis of $\beta$-amino acids or $\beta$-amino esters, difficulties were sometimes encountered in obtaining the desired compound as the sole product, which was usually accompanied by formation of $\beta$-lactams. Therefore, development of a novel and simple methodology for the selective preparation of $\beta$-amino acids and $\beta$-lactams is highly desirable in organic synthesis.

A straightforward manner for obtaining $\beta$-amino esters is thought to be the addition of Reformatsky reagents to aldimines; however, non-selective formation of $\beta$-amino esters and $\beta$-lactams in ratios depending on the conditions employed is

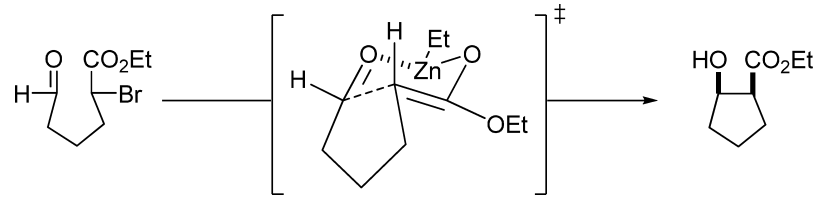

Fig. 4. Plausible Reaction Mechanism for Producing cis-Hydroxy Esters

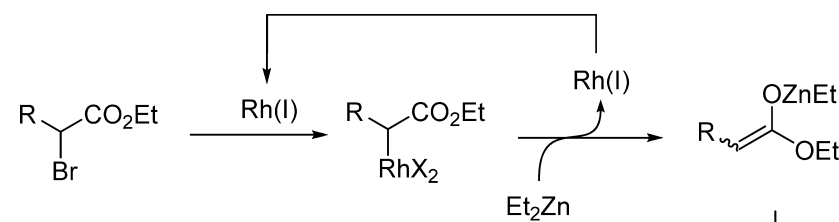

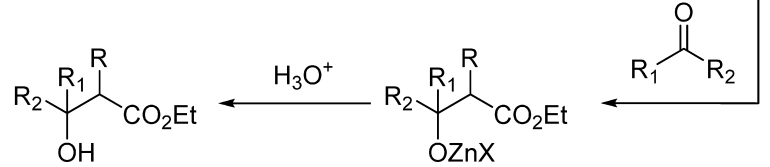

Fig. 5. Plausible Mechanism for Honda-Reformatsky Reaction

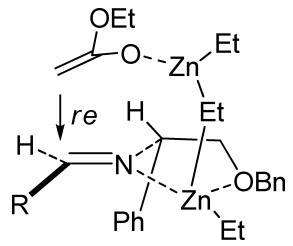

Fig. 6. Proposed Chiral Induction in the Honda-Reformatsky Reaction

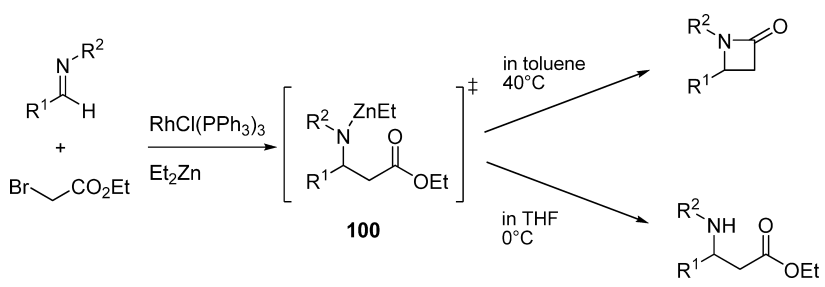

Chart 28. Selective Formation of $\beta$-Amino Esters and $\beta$-Lactams by Simply Changing the Reaction Conditions

often observed. ${ }^{86,87)}$ Fortunately, we were able to find the optimum reaction conditions for the synthesis of $\beta$-amino esters and $\beta$-lactams, selectively, from aldimines and ethyl bromoacetate by simply controlling the reaction conditions. When the reactions were carried out in THF at $0^{\circ} \mathrm{C}$ in the presence of $\mathrm{RhCl}\left(\mathrm{PPh}_{3}\right)_{3}(5 \mathrm{~mol} \%)$ and diethylzinc ( $4 \mathrm{~mol}$ equivalents), $\beta$-amino esters were produced exclusively in moderate to good yields without giving $\beta$-lactams regardless of the substituents on the aldimine nitrogens. On the other hand, $\beta$-lactams were selectively formed in toluene at $40^{\circ} \mathrm{C}$. However, in the case of aldimines possessing ortho-methoxyphenyl groups on the imine nitrogens, only $\beta$-amino esters were produced exclusively even in toluene at $40^{\circ} \mathrm{C}$ without giving $\beta$-lactams. The observations are in accordance with the results reported by Adrian and his co-workers, ${ }^{88)}$ and this fact suggests that the reactions also proceeded through similar zinc amide intermediates (100) under the rhodium-catalyzed reaction conditions for the conventional Reformatsky reaction as depicted in Chart 28.

Thus, we have succeeded in the preparation of $\beta$-amino esters and $\beta$-lactams, selectively, by simply changing the solvent and reaction temperature in the rhodium-catalyzed 


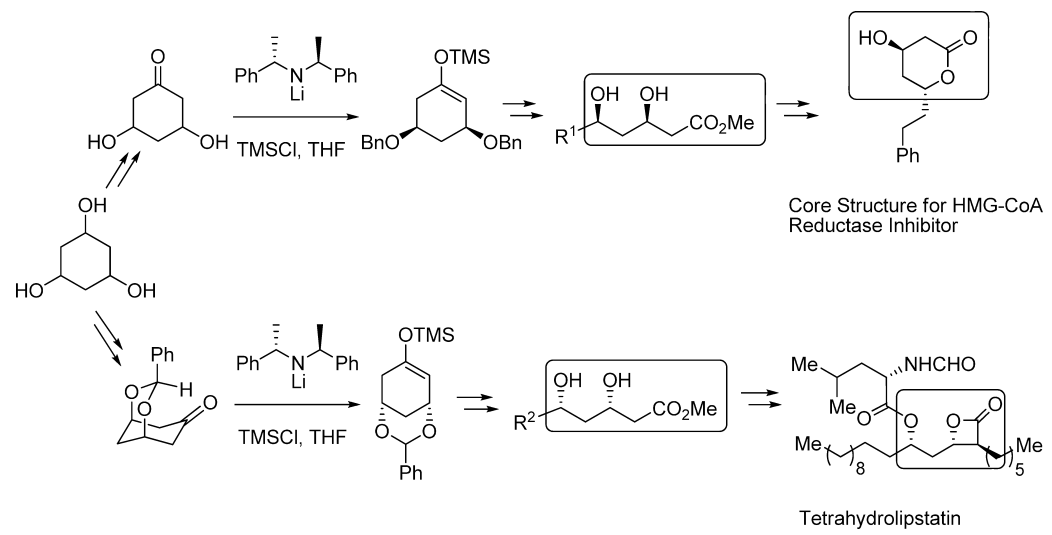

Chart 29. Enantioselective Synthesis of 1,3-syn-Dihydroxy Systems

Reformatsky-type reaction. ${ }^{76}$

The modified Reformatsky reaction that we developed here has been widely utilized in the synthesis of poly-fluorinated compounds ${ }^{89,90)}$ and also in the preparation of macrocyclic compounds, ${ }^{91,92)}$ and has been named the "Honda-Reformatsky reaction."

\section{Miscellaneous}

The development of enantioselective deprotonation of meso or prochiral compounds having a $\sigma$-plane by employing chiral lithium amide bases has provided an efficient and simple route for the synthesis of a wide variety of biologically active compounds including natural products in optically pure or rich forms. We have already applied this methodology to synthesis of the lactone moiety of an HMG-CoA reductase inhibitor and an antiobesity agent, (-)-tetrahydrolipstatin, in which the same synthetic strategy, the same starting material, and the same chiral amide base were employed to provide the corresponding 1,3-syn-dihydroxy systems with opposite stereochemistries to each other by devising the conformation of the starting material (Chart 29). Since these works including the synthesis of other types of bioactive compounds by application of this strategy have been summarized as a review article, this topic will not be discussed further here. ${ }^{93)}$

\section{Conclusion}

Throughout the history of medicinal chemistry, natural products have played important roles in discover and development of new medicines. The goal of medicinal chemistry is to find new biologically active compounds and make these compounds available to patients for therapeutic purposes including prophylaxis. However, even though newly discovered compounds have remarkable biological activities, there are many barriers and problems to be overcome for their therapeutic use as medicines. For example, the compounds should be stable both chemically and biochemically. Otherwise the compounds cannot reach the site of action. Also, the compounds should not have serious side effects. Of course, their physiological and physicochemical properties (ADMET), such as solubility in water and absorption from the gastrointestinal tract, are also important factors to devise new medicines. Moreover, we have to establish efficient synthetic procedures for the medicines to be widely available at reasonable prices. If a synthetic method for the desired compound has been established, preparation of a wide variety of its derivatives would easily be achieved, and such derivatives would provide great opportunities for development of novel attractive medicines.

Again, in order to obtain a wide variety of derivatives of biologically active compounds from the viewpoint of medicinal chemistry, it is essential to establish efficient synthetic procedures for desired targets. It is also desirable for newly developed reactions to be involved so as to establish efficient syntheses of the desired compounds.

Acknowledgements I would like to express sincere appreciation to my numerous coworkers whose efforts, persistence, and ability made possible the performance of the described research. Names of collaborators in the present study are mentioned in the References.

\section{References}

1) Honda T., Tsubuki M., J. Synth. Org. Chem. Jpn., 48, 43-55 (1990), and references cited therein.

2) Kametani T., Tsubuki M., Honda T., Chem. Pharm. Bull., 36, 37063709 (1988)

3) Kametani T., Tsubuki M., Tatsuzaki Y., Honda T., J. Chem. Soc., Perkin Trans. 1, 1990, 639-646 (1990).

4) Honda T., Kobayashi Y., Tsubuki M., Tetrahedron Lett., 31, 48914894 (1990).

5) Honda T., Kobayashi Y., Tsubuki M., Tetrahedron, 49, 1211-1222 (1993).

6) Honda T., Hoshi M., Tsubuki M., Heterocycles, 34, 1515-1518 (1992).

7) Honda T., Hoshi M., Kanai K., Tsubuki M., J. Chem. Soc., Perkin Trans. 1, 1994, 2091-2101 (1994).

8) Honda T., Imai M., Keino K., Tsubuki M., J. Chem. Soc., Perkin Trans. 1, 1990, 2677-2680 (1990).

9) Tsubuki M., Kanai K., Honda T., Heterocycles, 35, 281-288 (1993).

10) Tsubuki M., Kanai K., Nagase H., Honda T., Tetrahedron, 55, 2493-2514 (1999).

11) Honda T., Tomitsuka K., Tsubuki M., J. Org. Chem., 58, 4274-4279 (1993).

12) Honda T., "Structure and Chemistry (Part E)," Vol. 19, ed. by Atta-ur-Rahman, Elsevier, 1997, pp. 463-509.

13) Honda T., Kametani T., Tatsuzaki Y., Tsubuki M., J. Chem. Soc., Perkin Trans. 1, 1990, 1733-1737 (1990).

14) Honda T., Sano N., Kanai K., Heterocycles, 41, 425-429 (1995).

15) Honda T., Mizutani H., Kanai K., J. Chem. Soc., Perkin Trans. 1, 1996, 1729-1739 (1996).

16) Wu W.-L., Wu Y.-L., Tetrahedron, 49, 4665-4670 (1993).

17) Honda T., Ohta M., Mizutani H., Heterocycles, 46, 137-140 (1997).

18) Honda T., Heterocycles, 81, 2719-2747 (2010). 
19) Honda T., Heterocycles, 82, 1-46 (2011).

20) Honda T., Matsukawa T., Takahashi K., Org. Biomol. Chem., 9, 673-675 (2011).

21) Adams M., Pacher T., Greger H., Bauer R., J. Nat. Prod., 68, 83-85 (2004).

22) Brem B., Seger C., Pacher T., Hofer O., Vajrodaya S., Greger H., J. Agric. Food Chem., 50, 6383-6388 (2002).

23) Torssell S., Wanngren E., Somfai P., J. Org. Chem., 72, 4246-4249 (2007).

24) Kawatsura M., Kishi E., Kito M., Sakai T., Shirahama H., Matsuda F., Synlett, 1997 (Suppl. I), 479-480 (1997).

25) Suzuki K., Matsukawa H., Matsuo G., Koshino H., Nakata T., Tetrahedron Lett., 43, 8653-8655 (2002).

26) Hori N., Matsukawa H., Matsuo G., Koshino H., Nakata T., Tetrahedron, 58, 1853-1864 (2002).

27) Ito Y., Takahashi K., Nagase H., Honda T., Org. Lett., 13, 4640 4643 (2011).

28) Zhang Y.-M., Tan N.-H., He M., Lu Y., Shang S.-Q., Zheng S.-Q., Tetrahedron Lett., 45, 4319-4321 (2004).

29) Zhang Y.-M., Tan N.-H., Yang Y.-B., Lu Y., Cao P., Wu Y.-S., Chem. Biodivers., 2, 497-505 (2005).

30) Maity S., Ghosh S., Tetrahedron Lett., 48, 3355-3358 (2007).

31) Machrouhi F., Hamann B., Namy J. L., Kagan H. B., Synlett, 1996, 633-634 (1996).

32) Crabtree R. H., Davis M. W., J. Org. Chem., 51, 2655-2661 (1986).

33) For recent reviews of CBS reduction, see: Corey E. J., Heral C. J., Angew. Chem. Int. Ed., 37, 1986-2012 (1998).

34) For recent reviews of CBS reduction, see: Deloux L., Srebnik M., Chem. Rev., 93, 763-784 (1993).

35) Takahashi K., Honda T., Org. Lett., 12, 3026-3029 (2010).

36) Baldwin J. E., Turner S. C., Moloney M. G., Tetrahedron, 50, 9411-9424 (1994).

37) Baldwin J. E., Turner S. C., Moloney M. G., Tetrahedron, 50, 9425-9438 (1994).

38) Mizutani H., Takayama J., Soeda Y., Honda T., Tetrahedron Lett., 43, 2411-2414 (2002).

39) Mizutani H., Takayama J., Soeda Y., Honda T., Heterocycles, 62, 343-355 (2004).

40) Mizutani H., Takayama J., Honda T., Synlett, 2005, 328-330 (2005).

41) Shirafuji H., Tsubotani S., Ishimaru T., Harada S., PCT Int. Appl., 1991, WO 91 13,887 [Chem. Abstr., 116, 39780h].

42) Widzowski D., Wu E. S. C., Helander H. F., Drug Discov. Today, 2, 341-350 (1997).

43) Honda T., Shigehisa H., Org. Lett., 8, 657-659 (2006).

44) Kametani T., "The Chemistry of the Isoquinoline Alkaloids," Vol. 2, Kinkodo Publishing Company, Sendai, 1974, pp. 141-150.

45) Bhat S. V., Bhattacharya B. K., De Souza N. J., Dohadwalla A. N., Kohl H., Ger. Offen. 1977, CODEN: GWXXBX DE 2557282 19770707.

46) Berezhinskaya V. V., Trutneva E. A., Tr. Vses. Nauchno-Issled. Inst. Lek. Rast., 14, 66-69 (1971).

47) Shigehisa H., Takayama J., Honda T., Tetrahedron Lett., 47, 73017306 (2006).

48) Yang Y.-L., Chang F.-R., Wu Y.-C., Helv. Chim. Acta, 87, 1392 1399 (2004).

49) Chen C.-M., Fu Y.-F., Yang T.-H., J. Nat. Prod., 58, 1767-1771 (1995).

50) Corey E. J., Gin D. Y., Kania R. S., J. Am. Chem. Soc., 118, 9202 9203 (1996).

51) Honda T., Namiki H., Kaneda K., Mizutani H., Org. Lett., 6, 87-89 (2004).

52) Honda T., Namiki H., Watanabe M., Mizutani H., Tetrahedron Lett., 45, 5211-5213 (2004).

53) Murav'eva V. I., Ban'kovskii A. I., Dokl. Akad. Nauk SSSR, 110, 998-1000 (1956).

54) "Russian Pharmacopeia," 10th ed., Ministry of Health of the USSR,
Moscow, 1968, pp. 612-614.

55) Beutler J. A., Karbon E. W., Brubaker A. N., Malik R., Curtis D. R., Enna S. J., Brain Res., 330, 135-140 (1985).

56) Saito S., Iwamoto T., Tanaka T., Matsumura C., Sugimoto N., Horii Z., Tamura Y., Chem. Ind., 1263-1264 (1964).

57) Saito S., Tanaka T., Iwamoto T., Matsumura C., Sugimoto N., Horii Z., Makita M., Ikeda M., Tamura Y., J. Pharm. Soc. Jpn., 84, 1126-1133 (1964).

58) Mensah J. L., Gleye J., Moulis C., Fouraste I., J. Nat. Prod., 51, 1113-1115 (1988).

59) Lajis N. H., Guan O. B., Sargent M. V., Skelton B. W., White A. H., Aust. J. Chem., 45, 1893-1897 (1992).

60) Mensah J. L., Lagarde I., Ceschin C., Michel G., Gleye J., Fouraste I., J. Ethnopharmacol., 28, 129-133 (1990).

61) Tatematsu H., Mori M., Yang T.-H., Chang J.-J., Lee T. T.-Y., Lee K.-H., J. Pharm. Sci., 80, 325-327 (1991).

62) Thai D. L., Sapko M. T., Reiter C. T., Bierer D. E., Perel J. M., J. Med. Chem., 41, 591-601 (1998).

63) Grela K., Harutyunyan S., Michrewska A., Angew. Chem. Int. Ed., 41, 4038-4040 (2002)

64) For the original styrene ether ruthenium catalyst, see: Kingsbury J. S., Harrity J. P. A., Bonitatebus P. J. Jr., Hoveyda A. H., J. Am. Chem. Soc., 121, 791-799 (1999).

65) For the original styrene ether ruthenium catalyst, see: Garber S. B., Kingsbury J. S., Gray B. L., Hoveyda A. H., J. Am. Chem. Soc., 122, 8168-8179 (2000).

66) For the original styrene ether ruthenium catalyst, see: Hoveyda A. H., Gillingham D. G., Van Veldhuizen J. J., Kataoka O., Garber S. B., Kingsbury J. S., Harrity J. P., Org. Biomol. Chem., 2, 8-23 (2004).

67) Haight A. R., Stoner E. J., Peterson M. J., Grover V. K., J. Org. Chem., 68, 8092-8096 (2003).

68) Rudyanto M., Tomizawa Y., Morita H., Honda T., Org. Lett., 10, 1921-1922 (2008).

69) Mbatchi S. F., Mbatchi B., Banzouzi J. T., Bansimba T., Nsonde Ntandou G. F., Ouamba J. M., Berry A., Benoit-Vical F., J. Ethnopharmacol., 104, 168-174 (2006).

70) Sanon S., Ollivier E., Azas N., Mahiou V., Gasquet M., Ouattara C. T., Nebie I., Traore A. S., Esposito F., Balansard G., Timon-David P., Fumoux F., J. Ethnopharmacol., 86, 143-147 (2003).

71) Morita H., Oshimi S., Hirasawa Y., Koyama K., Honda T., Ekasari W., Indrayanto G., Zaini N. C., Org. Lett., 9, 3691-3693 (2007).

72) Kalivretenos A., Stille J. K., Hegedus L. S., J. Org. Chem., 56, 2883-2894 (1991).

73) Arcadi A., Cacchi S., Fabrizi G., Manna F., Pace P., Synlett, 1998, 446-448 (1998).

74) Kanai K., Wakabayashi H., Honda T., Org. Lett., 2, 2549-2551 (2000).

75) Honda T., Wakabayashi H., Kanai K., Chem. Pharm. Bull., 50, 307-308 (2002).

76) Kanai K., Wakabayashi H., Honda T., Heterocycles, 58, 47-51 (2002).

77) For recent reviews of the Reformatsky reaction, see: Fürstner A., Synthesis, 1989, 571-590 (1989).

78) For recent reviews of the Reformatsky reaction, see: Rathke M. W., Weipert P., "Comprehensive Organic Synthesis," Vol. 2, ed. by Trost B. M., Fleming I., Pergamon Press, Oxford, 1991, p. 277.

79) For recent reviews of the Reformatsky reaction, see: Fürstner A., "Organozinc Reagents," ed. by Knochel P., Jones P., Oxford University Press, New York, 1999, p. 287.

80) Vedejs E., Ahmad S., Tetrahedron Lett., 29, 2291-2294 (1988).

81) Dener J. M., Zhang L. H., Rapoport H., J. Org. Chem., 58, 11591166 (1993).

82) Binch H. M., Griffin A. M., Schwidetzky S., Ramsay M. V. J., Gallagher T., Lichtenthaler F. W., J. Chem. Soc., Chem. Commun., 1995, 967-968 (1995). 
83) Ding Y., Zhao G., J. Chem. Soc., Chem. Commun., 1992, 941-942 (1992).

84) Heathcock C. H., “Asymmetric Synthesis," Vol. 3, ed. by Morrison J. D., Academic Press, New York, 1984, p. 144.

85) Hansen M. M., Bartlett P. A., Heathcock C. H., Organometallics, 6, 2069-2074 (1987).

86) Mohan S., Sethi P. S., Kapoor A. L., J. Indian Chem. Soc., 48, 685-687 (1971).

87) Dardoize F., Moreau J.-L., Gaudemar M., Bull. Soc. Chim. Fr., 1972, 3841-3846 (1972).

88) Adrian J. C. Jr., Barkin J. L., Hassib L., Tetrahedron Lett., 40,
2457-2460 (1999).

89) Tarui A., Kondo K., Taira H., Sato K., Omote M., Kumadaki I., Ando A., Heterocycles, 73, 203-208 (2007).

90) Yamaki Y., Shigenaga A., Tomita K., Narumi T., Fujii N., Otaka A., J. Org. Chem., 74, 3272-3277 (2009).

91) Kigoshi H., Kita M., Ogawa S., Itoh M., Uemura D., Org. Lett., 5, 957-960 (2003).

92) Sato Y., Fukuda H., Tomizawa M., Masaki T., Shibuya M., Kanoh N., Iwabuchi Y., Heterocycles, 81, 2239-2246 (2010).

93) Honda T., J. Synth. Org. Chem. Jpn., 60, 1104-1111 (2002), and references cited therein. 